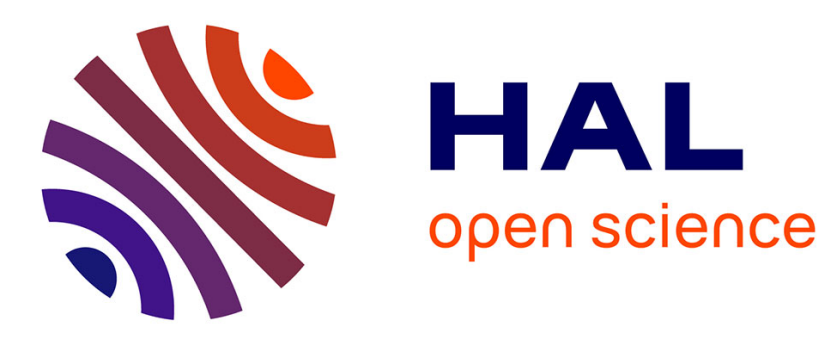

\title{
On the interplay between speculative bubbles and productive investment
}

Xavier Raurich, Thomas Seegmuller

\section{To cite this version:}

Xavier Raurich, Thomas Seegmuller. On the interplay between speculative bubbles and productive investment. European Economic Review, 2019, 111, pp.400-420. 10.1016/j.euroecorev.2018.11.002 . hal-02010648

\section{HAL Id: hal-02010648 \\ https://hal-amu.archives-ouvertes.fr/hal-02010648}

Submitted on 12 Feb 2020

HAL is a multi-disciplinary open access archive for the deposit and dissemination of scientific research documents, whether they are published or not. The documents may come from teaching and research institutions in France or abroad, or from public or private research centers.
L'archive ouverte pluridisciplinaire HAL, est destinée au dépôt et à la diffusion de documents scientifiques de niveau recherche, publiés ou non, émanant des établissements d'enseignement et de recherche français ou étrangers, des laboratoires publics ou privés. 


\title{
On the interplay between speculative bubbles and productive investment
}

\author{
Xavier Raurich*and Thomas Seegmuller ${ }^{\dagger \ddagger}$
}

November 1, 2018

\begin{abstract}
The aim of this paper is to study the interplay between long term productive investments and more short term and liquid speculative ones. A three-period lived overlapping generations model allows us to make this distinction. Agents have a portfolio decision. When young, they can invest in human capital that is a productive long term investment that provides a return during the following two periods. When young or in the middle age, they can invest in a bubble. Young individuals can also borrow on a credit market to finance the productive investment. However, the amount borrowed is limited by a credit constraint. We show that the existence of a stationary bubble raises productive investment and production when the bubleless economy is credit constrained and dynamically efficient. Indeed, young agents sell short the bubble to increase productive investments, whereas traders at middle age transfer wealth to old age. The bubble allows to relax the credit constraint. We outline that a permanent technological shock inducing either a larger return of capital in the short term or a similar increase in the return of capital in both periods raises productive capital, production and the bubble size. We use our framework to discuss the effect on the occurrence of bubbles of financial regulation and fiscal policy.
\end{abstract}

JEL classification: E22; E44; G12.

Keywords: Bubble; Efficiency; Vintage capital; Credit; Short sellers; Overlapping generations.

*Departament d'Economia and CREB, Universitat de Barcelona.

${ }^{\dagger}$ Corresponding author. Aix-Marseille University, CNRS, EHESS, Centrale Marseille, AMSE. 5-9 Boulevard Bourdet, CS 50498, 13205 Marseille Cedex 1, France. E-mail: thomas.seegmuller@univ-amu.fr.

¥This work has been carried out thanks to the support of the A*MIDEX project (ANR-11IDEX-0001-02) funded by the "Investissements d'Avenir" French Government program, the financial support of the French National Research Agency (ANR-15-CE33-0001-01) and the ECO2015-66701-R (MINECO-FEDER, UE) grant funded by the Government of Spain and Fondo Europeo de Desarrollo Regional. We thank an Editor and two Referees for their comments that really improve the paper. We also thank Raouf Boucekkine, Lise Clain-ChamossetYvrard, Michel Lubrano and participants to the 5th AMSE Workshop on Growth and Development, Marseille March 2015, to the PET conference, Luxembourg June 2015, and to the SAET conference, Cambridge July 2015, for useful comments and suggestions. 


\section{Introduction}

In recent years there is renewed interest in studying the link between productive and purely speculative investments. Some questions that naturally emerge are whether speculative investments are good or bad for capital accumulation and production, whether bubbles are compatible with dynamic efficiency, and what is the role played by speculative assets. To address these issues, the literature focuses on the case where one may invest either in productive capital or in an asset without fundamental value, which is a pure bubble when its price is positive (Tirole 1985), Weil (1987), Bosi and Seegmuller (2010), Fahri and Tirole (2012), Martin and Ventura (2012), Hirano and Yanagawa (2017)). ${ }^{1}$ In this literature, these two assets provide returns in the same period and are traded in each period. If we define liquidity as the capacity to immediately trade an asset, both assets have the same liquidity.

The purpose of this paper is to study the existence of bubbles and their effect on production when we introduce a differential in the liquidity of assets. As in Diamond and Dybvig (1983), we consider two assets that provide returns in different periods. In particular, there are a speculative asset which gives returns in the short run and can be traded in each period and a productive asset which is only purchased when young and provides returns in the longer run. Obviously, this distinction implies that the speculative asset is more liquid than the productive one. A clear example of investment with returns in the long term is investment in human capital through education. This investment takes place during youth, implies returns during the life-cycle, while it depreciates with death. Accordingly, in this paper, we will identify productive capital with human capital. ${ }^{2}$

The model we examine is an overlapping generations model with three-period lived households. When young, households can borrow through debt and invest in two assets: human capital, which is used in production and give returns in middle and old ages, and an asset without fundamental value, which is traded also in middle age. This asset is a bubble when it is positively valued. In this case, we roll over this asset. We assume that the amount invested is limited by a credit constraint that uses a fraction of the returns from human capital in middle age as collateral. A smaller value of this fraction limits the amount of credit. In middle age, agents finance credit and can invest only in the bubble to transfer purchasing power to old age. ${ }^{3}$ It is important to underline that this framework introduces the notion that capital investment is less liquid than the speculative investment.

In accordance with the empirical evidence showing that bubbles occur in periods of large GDP growth (Caballero et al. (2006), Martin and Ventura

\footnotetext{
${ }^{1}$ There are however some exceptions. See for instance Kamihigashi (2008).

${ }^{2}$ Other examples of productive investments with a long term return are real estate, infrastructure, equipment and software, or research and development.

${ }^{3}$ In the middle age, agents do not invest in the productive asset because, at the equilibrium with bubble we focus on, they will prefer to reallocate income across generations using the speculative bubble.
} 
(2012)), we show that bubbles may be productive because they are able to raise production through larger investments in human capital. Considering that the credit constraint is binding at the bubbleless steady state and that this steady state is dynamically efficient, we show that the bubbly steady state features a higher level of production, because the bubble is used to finance productive investment and relax the binding credit constraint. Therefore, our model is also consistent with the empirical evidence which highlights that credit is higher in periods of expansions (Martin and Ventura (2016)) and of bubbles (Jorda et al. $(2015))$.

The underlying mechanism explaining the former results is based on the interaction between two effects, a crowding-in effect through credit and a crowdingout effect through saving. The first one corresponds to the fact that young agents sell short the speculative asset to finance investment in productive human capital when the bubbleless steady state is dynamically efficient and credit constrained. This allows to have a larger human capital and production than in the credit constrained bubbleless economy. Selling short the speculative asset can be an equilibrium because middle age agents reimburse the amount borrowed and also buy the speculative asset to transfer purchasing power to old age. This saving in middle age allows to have a bubble with finite value in equilibrium and it corresponds to the crowding-out effect, which allows to reach the golden rule and also to give a positive value to the bubble. Hence, starting with a dynamically efficient bubbleless steady state, which is the most plausible assumption (Abel et al. (1989)), the bubbly steady state attains the golden rule.

The bubble reallocates the income of middle age households to young and old ones. This means that the demographic structure of overlapping generations play a key role because, first, some agents are able to be short sellers of the bubble asset and second, there are heterogeneous investors in the market, young and middle age agents. ${ }^{4}$ It is already known that heterogeneous investment opportunities play a key role to generate bubbles enhancing production (Hirano and Yanagawa (2017), Kocherlakota (2009)). We contribute to this literature by showing that a productive bubble also arises if it reallocates resources towards young agents, by generating liquidity used to raise human capital. ${ }^{5}$

Since the long term investment in human capital is a key element of our story, we study the effect on the level of capital and bubble in the long-run of different types of permanent technological shocks that modify the short and long run returns of productive investment. We compare the steady states before and after the shock and we show that a biased technological shock implying a larger return in the longer term may reduce capital. This happens because the bubble may disappear and, hence, it can no more be used to finance productive investment. On the contrary, if the technological shock is biased toward short term return of capital or increases the returns of capital in the short and long terms in

\footnotetext{
${ }^{4}$ Note that in models with infinitely lived agents, short sale positions cannot sustain the existence of a bubble. See Kocherlakota (1992) for more details.

${ }^{5}$ Note that we can find an alternative approach of liquidity in Lagos and Wright (2005) and Lagos (2010).
} 
like manner, we observe an increase in capital, production and bubble size. These shocks are typically the result of innovations. Then, our results explain that episodes of bubbles are associated with new innovations, as is documented and discussed in several contributions (see for instance Caballero et al. (2006), Lansing (2008, 2012), Scheinkman (2013)).

We further apply our framework to the debate on the design of the fiscal policy that aims to promote long term investment (Wehinger (2011)). We show that the difference between human capital and labor income taxes determines both the existence and the nature of the bubble, productive or unproductive. ${ }^{6}$ Moreover, we highlight that the suitable fiscal policy to promote long term investment crucially depends on the existence and nature of bubbles.

Finally, to clarify the contribution of this paper, we recall that first results in the literature show that investment in a speculative bubble reduces capital accumulation in the long run to reach the golden rule (Tirole (1985)). This requires that the steady state without bubble is dynamically inefficient. ${ }^{7}$ Dynamic inefficiency has been criticized by Abel et al. (1989) for its lack of empirical relevance and, moreover, the lower level of production when there is a bubble is not observed in data, as it is for instance illustrated by Caballero et al. (2006) and Martin and Ventura (2012). Recently, several papers have provided answers to these two criticisms. First, Martin and Ventura $(2012,2016)$ show the existence of productive bubbles when there are heterogeneous returns of capital investments and there is a process of bubble creation. Second, Fahri and Tirole (2012) and Hirano and Yanagawa (2017) show the existence of productive bubbles when a financial constraint is introduced. In these papers, the bubble generates an investment multiplier effect. Third, Kocherlakota (2009), and Miao and Wang (2011) also consider financial constraints that attribute to the bubble the role of collateral. As the bubbles allows to borrow larger amounts, it becomes productive. ${ }^{8}$ Our paper contributes to this literature on the existence of productive bubbles. However, we differ from the first papers because our analysis does not need bubble shocks and from the last ones because our result precisely relies on the role of the bubble in relaxing a binding credit constraint. We show that the economy attains a larger aggregate production in the bubbly economy, when the bubbleless one is credit constrained and dynamically efficient. In contrast to Martin and Ventura (2016), the crowding-in dominates the crowding out effect when the bubble allows the credit constraint to be no more binding.

This paper is organized as follows. In the next section, we present our framework. In Section 3, we study the equilibria without and with bubbles to show the existence of productive bubbles. In Section 4, we discuss the effect of technological shocks. Section 5 is devoted to study the effect of fiscal policy.

\footnotetext{
${ }^{6}$ Taxes on human capital income must be interpreted as the tax rate on high wages, which are typically associated with high skills (human capital). In contrast, taxes on labor income must be interpreted as the tax rates on low (unskilled) wages.

${ }^{7} \mathrm{As}$ it is well-known, this idea was already emphasized in the model without capital accumulation by Samuelson (1958).

${ }^{8}$ See Miao (2014) for a short survey of this recent literature.
} 
Section 6 concludes, while many technical details are relegated to the Appendix.

\section{Model}

Time is discrete $(t=0,1, \ldots,+\infty)$ and there are two types of agents, households and firms.

\subsection{Households}

We consider an overlapping generations economy with constant population size. Each generation is populated by a continuum of mass one of agents that live for three periods. Each household has utility for consumption at each period of time. Preferences of an individual born in period $t$ are represented by the following utility function:

$$
u\left(c_{1, t}\right)+\beta u\left(c_{2, t+1}\right)+\beta^{2} u\left(c_{3, t+2}\right)
$$

where $\beta \in(0,1)$ is the subjective discount rate and $c_{j, t}$ amounts for consumption when young $(j=1)$, in middle age $(j=2)$, and when old $(j=3)$. For tractability, we assume that $u\left(c_{j, t}\right)=\ln c_{j, t}$.

The household supplies one unit of labor when young. She shares her labor income, given by the wage $w_{t}$, between consumption $c_{1, t}$ and a portfolio of three assets: productive capital $h_{t+1}$, debt $d_{t}$ and a speculative asset $b_{1, t}$. On the one hand, to capture the idea that, in contrast to investing in the liquid speculative asset, productive investment is less liquid and engages the household in the long term, we assume that capital provides a return $\phi_{1} q_{t+1}$ in the second period of life and a return $\phi_{2} q_{t+2}$ in the third period. We also assume that capital depreciates completely after being used in production. These properties of productive capital in this model are those of human capital: it is a long term investment done by young individuals that completely depreciates at the end of life. Accordingly, we interpret $h_{t+1}$ as human capital. On the other hand, we assume that each young household may incur a debt $d_{t}$ that will be reimbursed in middle age $R_{t+1}^{d} d_{t}$. This loan is granted by middle age households living at the same period and it will be reimbursed when they are old.

The middle age household shares her income coming from human capital, the return on the speculative asset $R_{t+1}$ and the payment of the debt accumulated when young between consumption $c_{2, t+1}$, the debt lent to young households $d_{t+1}$ and a new investment in the speculative asset $b_{2, t+1}$. Finally, when old, the household's consumption $c_{3, t+1}$ is equal to her income coming from the return of human capital, the reimbursement of debt made by middle age agents and the investment in the speculative asset done in middle age and remunerated at the return $R_{t+2}$. Accordingly, the budget constraints in each period of life of 
an agent born in period $t$ are:

$$
\begin{gathered}
c_{1, t}+h_{t+1}+b_{1, t}=w_{t}+d_{t} \\
c_{2, t+1}+b_{2, t+1}+d_{t+1}=\phi_{1} q_{t+1} h_{t+1}+R_{t+1} b_{1, t}-R_{t+1}^{d} d_{t} \\
c_{3, t+2}=\phi_{2} q_{t+2} h_{t+1}+R_{t+2} b_{2, t+1}+R_{t+2}^{d} d_{t+1}
\end{gathered}
$$

As argued by Scheinkman (2013), borrowers are often forced to cover their short positions with collateral. Following Hirano and Yanagawa (2017), Le Van and Pham (2016) and Martin and Ventura (2016), credit and short sales on the speculative asset are limited by the following constraint: ${ }^{9}$

$$
R_{t+1}^{d} d_{t}-R_{t+1} b_{1, t} \leqslant \theta \phi_{1} q_{t+1} h_{t+1}
$$

with $\theta \in[0,1)$. This constraint limits the borrowing possibilities of young agents. In particular, we assume that the reimbursement in middle age of credit and short sales on the speculative asset is limited by the returns on human capital at this period. Hence, if this constraint is binding, human capital acts as a collateral. The parameter $\theta$ measures the borrowing limit. If $\theta=0$, credit and short sales are not possible. As $\theta$ increases, the constraint relaxes. We interpret $\theta$ as a policy parameter set through regulations. Note that (5) also implies that the income in middle age is strictly positive. Finally, we do not introduce such a constraint on the investment decision in middle age, because middle age agents do not borrow through credit and bubble short sales, meaning that the introduction of such a constraint is irrelevant. In the following, we call a constrained equilibrium (steady state), an equilibrium (steady state) where the constraint (5) is binding.

The household determines her optimal choices maximizing her utility (1) under the budget constraints (2)-(4) and the credit constraint (5). By direct inspection of her program and by lack of arbitrage opportunity, we immediately deduce that $R_{t+1}^{d}=R_{t+1}$ for all $t$. We can then define $x_{1, t}=b_{1, t}-d_{t}$ and $x_{2, t}=b_{2, t}+d_{t}$, and rewrite the constraints (2)-(5) as follows:

$$
\begin{aligned}
c_{1, t}+h_{t+1}+x_{1, t} & =w_{t} \\
c_{2, t+1}+x_{2, t+1} & =\phi_{1} q_{t+1} h_{t+1}+R_{t+1} x_{1, t} \\
c_{3, t+2} & =\phi_{2} q_{t+2} h_{t+1}+R_{t+2} x_{2, t+1} \\
R_{t+1} x_{1, t} & \geqslant-\theta \phi_{1} q_{t+1} h_{t+1}
\end{aligned}
$$

At this point, it is important to clarify the interpretation of the returns of the two assets: human capital and the speculative asset. On the one hand, the returns of human capital obtained in the second and third periods of life can be interpreted as the wage of skilled workers, the skill being acquired during youth. The wage $w_{t}$ obtained in the first period of life will be simply the labor compensation of unskilled young workers. Moreover, since human capital

\footnotetext{
${ }^{9}$ Short sales on the speculative asset imply $b_{1, t}<0$. In this case, young individuals use the speculative asset to finance investment.
} 
investment provides returns in the following two periods, this introduces the difference between short term speculative investments and long term productive investments, the first ones being more liquid than the second ones, which is the key ingredient of our story.

On the other hand, we clarify that the speculative asset is supplied in one unit at a price $p_{t}$ at period $t$. New investments in this asset by young and middle age agents are in quantities $\epsilon_{t}$ and $1-\epsilon_{t}$, respectively. Therefore, the values of this asset bought or sold by these agents are $b_{1, t}=p_{t} \epsilon_{t}$ and $b_{2, t}=p_{t}\left(1-\epsilon_{t}\right)$. Of course, if either $b_{1, t}<0$ or $b_{2, t}<0$, one type of trader is a short seller of this asset. It corresponds to equilibria where either $\epsilon_{t}<0$ or $\epsilon_{t}>1$. Finally, since this asset has no fundamental value, it is a bubble if $p_{t}=b_{1, t}+b_{2, t}>0$, whereas there is no bubble if $p_{t}=b_{1, t}+b_{2, t}=0$ and $b_{1, t}=b_{2, t}=0$. Taking into account the definition of the variables $b_{1, t}$ and $b_{2, t}$, we obtain:

$$
b_{1, t+1}+b_{2, t+1}=R_{t+1}\left(b_{1, t}+b_{2, t}\right)
$$

where the left-hand side of (10) measures the value of the bubble net purchasing in period $t+1$ and the right-hand side the value of the net sales in that period. It follows that the return $R_{t+1}$ is the growth factor of the bubble price. Finally, using the definitions of $x_{1, t}$ and $x_{2, t}$, equation (10) rewrites as:

$$
x_{1, t+1}+x_{2, t+1}=R_{t+1}\left(x_{1, t}+x_{2, t}\right)
$$

The variable $x_{1, t}$ measures the value of the short term assets used to smooth consumption between the first two periods of life, whereas $x_{2, t}$ measures the value of the short term assets used to smooth consumption between the last two periods. When these variables take a positive value, individuals use the short term assets to postpone consumption and they use these assets to borrow when they take a negative value. To clarify the interpretation of short term assets, it is important to distinguish between two different cases. First, if $x_{1, t}+x_{2, t}=0$, $x_{1, t}=-d_{t}$ and $x_{2, t}=d_{t}$, then the short term asset is simply credit. In contrast, if $x_{1, t}+x_{2, t}>0$, short term assets involve a bubble.

An equilibrium where $x_{1, t}+x_{2, t}>0$, i.e. $b_{1, t}+b_{2, t}>0$, can alternatively be interpreted as a situation with a bubble on credit. With this interpretation of our short term assets, there is a market for assets that value credit. When young individuals obtain a credit from a financial institution, this institution can sell this asset to another financial institution that buys it using the deposits of middle age individuals. When the demand of this asset is larger than the supply of credit, there is a bubble. Such a situation clearly corresponds to our scheme where young individuals sell (short) a speculative asset to middle age individuals.

Households maximize the utility (1) subject to the budget constraints (6)-(8) and the credit constraint (9). ${ }^{10}$ The solution of the household's problem when

\footnotetext{
${ }^{10}$ See Appendix A.1 for more details. Note also that we focus on deterministic equilibria, since we do not directly consider the crash of the bubble as a stochastic process. As explained in Appendix B.2, the introduction of a stochastic process does not provide new additional ingredients to explain the occurrence of productive bubbles.
} 
the credit constraint is binding is given by the following equations:

$$
\begin{aligned}
x_{1, t} & =-\theta \phi_{1} \frac{q_{t+1}}{R_{t+1}} h_{t+1} \\
c_{3, t+2} & =\beta R_{t+2} c_{2, t+1} \\
c_{2, t+1}\left(1-\theta \phi_{1} \frac{q_{t+1}}{R_{t+1}}\right) & =\beta\left[(1-\theta) \phi_{1} q_{t+1}+\phi_{2} \frac{q_{t+2}}{R_{t+2}}\right] c_{1, t}
\end{aligned}
$$

and the constraint is binding if $c_{2, t+1}>\beta R_{t+1} c_{1, t}$. On the contrary, if the credit constraint is not binding, the solution of the household's problem is given by the following equations:

$$
\begin{gathered}
c_{2, t+1}=\beta R_{t+1} c_{1, t} \\
c_{3, t+2}=\beta R_{t+2} c_{2, t+1} \\
1=\frac{\phi_{1} q_{t+1}}{R_{t+1}}+\frac{\phi_{2} q_{t+2}}{R_{t+1} R_{t+2}}
\end{gathered}
$$

\section{$2.2 \quad$ Firms}

Firms produce with the following technology:

$$
Y_{t}=H_{t}^{\alpha} L^{1-\alpha}, \text { with } \alpha \in(0,1 / 2)
$$

where $L$ is the number of young workers and $H_{t}$ is aggregate productive capital composed by the stock of human capital of generations born at period $t-1$ and $t-2$. Since households, that live three periods, invest in human capital when young and this investment has returns in middle and old ages, human capital is two-period lived, and completely depreciates after. We assume that the different human capitals are perfect substitutes in the production

$$
H_{t}=\phi_{1} h_{t}+\phi_{2} h_{t-1}
$$

where $\phi_{1}>0$ and $\phi_{2}>0$ measure the productivities of the human capital of the generations born in $t-1$ and $t-2$, respectively. ${ }^{11}$ In a sense, $h_{t}$ corresponds to vintage capital of the One-Hoss Shay type with a lifetime of two periods, but with different productivities during the lifetime (see Benhabib and Rustichini (1991) and Boucekkine et al. (2005a)).

Since $L=1$, profit maximization under perfect competition implies that the wage $w_{t}$ and the return $q_{t}$ from aggregate human capital $H_{t}$ are given by:

$$
\begin{gathered}
w_{t}=(1-\alpha) H_{t}^{\alpha} \\
q_{t}=\alpha H_{t}^{\alpha-1}
\end{gathered}
$$

\footnotetext{
${ }^{11}$ We do not allow to have $\phi_{2}=0$. Indeed, in this case, capital is no more a long term asset.
} 


\section{Existence of productive bubbles}

We recall that a bubble is productive if the levels of human capital and production at a steady state with bubble are larger than the levels attained at a steady state without bubble. Our purpose is to show that the speculative bubble can be productive when it relaxes the credit constraint and promotes investment in human capital. Therefore, we will analyze and compare the credit constrained bubbleless steady state and the unconstrained bubbly steady state. In Appendix B.1, we characterize the constrained bubbly steady state and show that the bubble cannot be productive in this case. Hence, the bubble is productive when it facilitates the access to credit, by making the credit constraint unbinding.

\subsection{Constrained bubbleless steady state}

We first analyze the model without bubble, i.e. $b_{1, t}=b_{2, t}=0$, and with the credit constraint (9) binding. In this case, $x_{2, t}=-x_{1, t}$. Using (12), the budget constraints (6)-(8) rewrite as:

$$
\begin{aligned}
c_{1, t} & =w_{t}-h_{t+1}\left(1-\frac{\theta \phi_{1} q_{t+1}}{R_{t+1}}\right) \\
c_{2, t+1} & =(1-\theta) \phi_{1} q_{t+1} h_{t+1}-\frac{\theta \phi_{1} q_{t+2} h_{t+2}}{R_{t+2}} \\
c_{3, t+2} & =q_{t+2}\left(\theta \phi_{1} h_{t+2}+\phi_{2} h_{t+1}\right)
\end{aligned}
$$

Substituting (21)-(23) into (13) and (14), we get:

$$
\begin{gathered}
q_{t+2}\left[\theta \phi_{1}(1+\beta) h_{t+2}+\phi_{2} h_{t+1}\right]=\beta R_{t+2}(1-\theta) \phi_{1} q_{t+1} h_{t+1} \\
1-\frac{\theta \phi_{1} q_{t+1}}{R_{t+1}}=\beta \frac{\left[\phi_{1} q_{t+1}(1-\theta)+\frac{\phi_{2} q_{t+2}}{R_{t+2}}\right]\left[w_{t}-h_{t+1}\left(1-\frac{\theta \phi_{1} q_{t+1}}{R_{t+1}}\right)\right]}{(1-\theta) \phi_{1} q_{t+1} h_{t+1}-\frac{\theta \phi_{1} q_{t+2} h_{t+2}}{R_{t+2}}}
\end{gathered}
$$

and, using (14), the credit constraint is binding if:

$$
(1-\theta) \phi_{1} q_{t+1}+\phi_{2} \frac{q_{t+2}}{R_{t+2}}>R_{t+1}\left(1-\theta \phi_{1} \frac{q_{t+1}}{R_{t+1}}\right)
$$

Definition 1 Given $h_{-1}>0$ and $h_{0}>0$, a credit constrained equilibrium without bubble is a path of $\left\{h_{t}, q_{t}, R_{t}, w_{t}, H_{t}\right\}_{t=0}^{\infty}$ that solves equations (18), (19), (20), (24), and (25), and satisfies (26). ${ }^{12}$

\footnotetext{
${ }^{12}$ We limit the analysis to the steady state equilibrium. However, we have numerically obtained the transition, which exhibits monotonic convergence towards the steady state. Section 4 shows this transition.
} 
At an interior steady state, we have $w / h=q\left(\phi_{1}+\phi_{2}\right)(1-\alpha) / \alpha$. Using equations (18), (20), (24) and (25), we deduce that:

$$
\begin{gathered}
R=\frac{\theta \phi_{1}(1+\beta)+\phi_{2}}{\beta(1-\theta) \phi_{1}} \equiv \underline{R} \\
q=\frac{1}{\frac{\beta(1+\beta)}{1+\beta+\beta^{2}}\left(\phi_{1}+\phi_{2}\right) \frac{1-\alpha}{\alpha}+\frac{\phi_{1}^{2} \beta(1-\theta) \theta}{\theta \phi_{1}(1+\beta)+\phi_{2}}} \equiv \underline{q} \\
h=\left(\frac{\alpha}{q}\right)^{\frac{1}{1-\alpha}} \frac{1}{\phi_{1}+\phi_{2}} \equiv \underline{h}
\end{gathered}
$$

At this steady state the credit constraint must be binding, which requires $c_{2}>\beta \underline{R} c_{1}$. Using (26), this is satisfied at a steady state if $\underline{R}<1$ and:

$$
\frac{\phi_{1} \underline{q}(1-\theta)+\phi_{2} \underline{q} / \underline{R}}{1-\frac{\theta \phi_{1} \underline{q}}{\underline{\underline{R}}}}>1
$$

The first inequality is satisfied for

$$
\theta<\frac{\beta \phi_{1}-\phi_{2}}{\phi_{1}(1+2 \beta)} \equiv \bar{\theta} \text { and } \phi_{2} / \phi_{1}<\beta
$$

Since $\underline{R}>\theta \phi_{1} \bar{q}$, the second inequality is equivalent to

$$
1-\frac{\theta \phi_{1}(1+\beta)+\phi_{2}}{\theta \phi_{1}+\phi_{2}} \frac{\beta}{1+\beta+\beta^{2}} \frac{\phi_{1}+\phi_{2}}{\phi_{1}} \frac{1-\alpha}{\alpha}>\theta .
$$

The left-hand side is decreasing in $\theta$ and strictly smaller than 1 , whereas the right-hand side is of course linearly increasing in $\theta$. Hence, there exist a $\widetilde{\theta}<1$ such that the previous inequality holds if $\theta<\widetilde{\theta}$ and

$$
\frac{\alpha}{1-\alpha}>\frac{\phi_{1}+\phi_{2}}{\phi_{1}} \frac{\beta}{1+\beta+\beta^{2}}
$$

The previous arguments are summarized in the following proposition:

Proposition 1 There is a unique constrained bubbleless steady state $\underline{h}$ if:
1. $\theta<\min \{\bar{\theta}, \widetilde{\theta}\}$
2. $\phi_{2} / \phi_{1}<\beta$;
3. $\frac{\alpha}{1-\alpha}>\frac{\phi_{1}+\phi_{2}}{\phi_{1}} \frac{\beta}{1+\beta+\beta^{2}}$.

At a steady state, the resource constraint on the goods market writes as $c_{1}+c_{2}+c_{3}=\left[\left(\phi_{1}+\phi_{2}\right) h\right]^{\alpha}-h$, where the left-hand side of the resource constraint is total consumption at the steady state and the right-hand side is production net of investment. The steady state is dynamically efficient if it is not possible to increase total consumption at one date without decreasing total consumption 
at another date. De la Croix and Michel (2002, pages 82-90) show that the steady state is dynamically efficient when there is underaccumulation of capital, which occurs when net production increases with capital investment. They also show that an equilibrium is Pareto optimal when there is under-accumulation, meaning that dynamic efficiency where total consumption is maximized also implies lifetime utility maximization. It can be shown that this occurs when the net return of investment is positive, i.e. $\left(\phi_{1}+\phi_{2}\right) q>1 .^{13}$ Using equation (28), this is satisfied under the following condition:

$$
\frac{\alpha}{1-\alpha}>\frac{\beta(1+\beta)}{1+\beta+\beta^{2}}+\frac{\alpha}{1-\alpha}\left(\frac{\phi_{1}}{\phi_{1}+\phi_{2}}\right)\left(\frac{\phi_{1} \beta(1-\theta) \theta}{\theta \phi_{1}(1+\beta)+\phi_{2}}\right)
$$

The right hand side of the dynamic efficiency condition is the saving rate for human capital investment over the wage $\underline{h} / \underline{w}$. Therefore, the dynamic efficiency condition states that this saving rate must be smaller than $\alpha /(1-\alpha)$.

\subsection{Unconstrained bubbly steady state}

We study now the unconstrained equilibrium with a positive bubble, i.e. $x_{1, t}+$ $x_{2, t}>0$. Therefore, we use the first order conditions of the consumers' problem when the credit constraint is not binding and the budget constraints to obtain the following definition.

Definition 2 Given $h_{-1}>0$ and $h_{0}>0$, an equilibrium with bubbles is a path of $\left\{h_{t}, H_{t}, R_{t}, q_{t}, w_{t}, c_{1, t}, c_{2, t}, c_{3, t}, x_{1, t}, x_{2, t}\right\}_{t=0}^{\infty}$ that satisfies the budget constraints (6), (7) and (8), the market clearing conditions (11) and (18), the competitive factor payments (19) and (20), and the first order conditions (15), (16) and (17).

We proceed to obtain the steady state of this equilibrium. From (11), a bubbly steady state is such that $R=1$. From (17) and (20), we obtain:

$$
\begin{aligned}
q & =1 /\left(\phi_{1}+\phi_{2}\right) \equiv \bar{q} \\
h & =\alpha^{\frac{1}{1-\alpha}}\left(\phi_{1}+\phi_{2}\right)^{\frac{\alpha}{1-\alpha}} \equiv \bar{h}
\end{aligned}
$$

Note that (34) implies that the bubbly steady state maximizes the production net of investment and, hence, this bubbly steady state attains the golden rule. Indeed, the golden rule is defined as the steady state stock of human

\footnotetext{
${ }^{13}$ In order to obtain the condition for dynamic inefficiency, we first use the resource constraint to obtain that total consumption, $c_{t}$, satisfies $c_{t}=\left[\phi_{1} h_{t}+\phi_{2} h_{t-1}\right]^{\alpha}-h_{t+1}$. Using this equation, the introduction of a permanent reduction of investment in period $t$, $d h_{t+1}=d h_{t+j}<0$ for all $j \geq 1$, has the following effects on total consumption: $d c_{t}=-d h_{t+1}$, $d c_{t+1}=\left(\phi_{1} q_{t+1}-1\right) d h_{t+1}$ and $d c_{t+j}=\left[\left(\phi_{1}+\phi_{2}\right) q_{t+j}-1\right] d h_{t+1}$ for all $j \geq 1$. From these expressions, it follows that if $\left(\phi_{1}+\phi_{2}\right) q<1$ then a permanent reduction in investment implies an increase in total consumption in all dates and, hence, the equilibrium is dynamically inefficient.
} 
capital that maximizes total consumption at a stationary path and, hence, it is the stock of human capital that maximizes production net of investment. Note that this implies that any regulation or fiscal policy will reduce welfare in this economy. It also implies that the level of welfare at a steady state with bubbles is larger than the level of welfare attained at a steady state without bubbles.

Next, we use (15) and (16) to obtain $c_{2}=\beta c_{1}$ and $c_{3}=\beta^{2} c_{1}$. We substitute these two relationships and $w / h=q\left(\phi_{1}+\phi_{2}\right)(1-\alpha) / \alpha=(1-\alpha) / \alpha$ in (6)-(8) to obtain:

$$
\begin{aligned}
x_{2} & =\left(\frac{\beta^{2}}{1+\beta+\beta^{2}}-\frac{\phi_{2}}{\phi_{2}+\phi_{1}} \frac{\alpha}{1-\alpha}\right) \bar{w} \equiv \bar{x}_{2} \\
x_{1} & =\left(\frac{\beta(1+\beta)}{1+\beta+\beta^{2}}-\frac{\alpha}{1-\alpha}\right) \bar{w} \equiv \bar{x}_{1} \\
\bar{x}_{1}+\bar{x}_{2} & =\left(\frac{\beta+2 \beta^{2}}{1+\beta+\beta^{2}}-\frac{2 \phi_{2}+\phi_{1}}{\phi_{2}+\phi_{1}} \frac{\alpha}{1-\alpha}\right) \bar{w}
\end{aligned}
$$

where $\bar{w}=(1-\alpha) \bar{h} / \alpha$ is the equilibrium wage.

The existence of this steady state depends on the bubble being positive, $\bar{x}_{1}+\bar{x}_{2}>0$, and the constraint being non-binding. While the first condition immediately follows from (38), the second condition follows from assuming that the constraint (9) holds in strict inequality in this steady state, i.e. $\bar{x}_{1}>$ $-\theta \phi_{1} \bar{q} \bar{h}$. Using (34), (35) and (37), the constraint is non-binding when:

$$
\theta>\theta^{*} \equiv\left(\frac{\phi_{1}+\phi_{2}}{\phi_{1}}\right)\left[1-\left(\frac{1-\alpha}{\alpha}\right)\left(\frac{\beta(1+\beta)}{1+\beta+\beta^{2}}\right)\right]
$$

The following proposition establishes the existence of an unconstrained bubbly steady state:

Proposition 2 There is a unique bubbly steady state $\bar{h}$ if and only if:

1. $\theta>\theta^{*}$;

2. $\frac{\alpha}{1-\alpha}<\frac{\beta+2 \beta^{2}}{1+\beta+\beta^{2}} \frac{\phi_{2}+\phi_{1}}{2 \phi_{2}+\phi_{1}}$.

\subsection{Productive bubbles}

We proceed to prove the existence of productive bubbles by showing that the equilibrium stock of human capital is larger at the bubbly steady state than at the bubbleless one. However, we first must guarantee that both steady states may coexist.

Proposition 3 The unconstrained bubbly steady state $(\bar{h})$ and the constrained

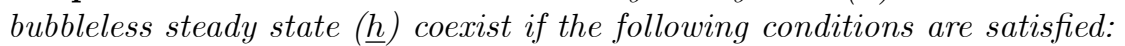

1. $\frac{\phi_{2}}{\phi_{1}}<\beta$ 


$$
\begin{aligned}
& \text { 2. } \theta^{*}<\theta<\widetilde{\theta} \text {; } \\
& \text { 3. } \frac{\phi_{1}+\phi_{2}}{\phi_{1}} \frac{\beta}{1+\beta+\beta^{2}}<\frac{\alpha}{1-\alpha}<\frac{\beta(1+2 \beta)}{1+\beta+\beta^{2}} \frac{\phi_{1}+\phi_{2}}{\phi_{1}+2 \phi_{2}} \text {. }
\end{aligned}
$$

Proof. See Appendix A.2.

Recall that the parameter $\theta$ determines the strength of the credit constraints and can be interpreted as a policy parameter that measures the degree of regulation in the financial sector. The larger $\theta$ is, the more deregulated is the financial sector, since a young trader is less constrained to increase her borrowing. Therefore, the value of this parameter crucially determines the existence of the two steady states. On the one hand, if $\theta$ is low, $\theta<\theta^{*}$, the constraint becomes binding in the bubbly equilibrium. On the other hand, if $\theta$ is too large, $\theta>\widetilde{\theta}$, the credit constraint in the bubbleless equilibrium may be non-binding. Therefore, the coexistence of the two steady states occurs for intermediate values of $\theta, \theta \in\left(\theta^{*}, \tilde{\theta}\right)$. This result can be connected to some findings of Fahri and Tirole (2012), who rather interpret $\theta$ as the degree of pledgeability. In contrast to them, a bubble may exist if the degree of pledgeability is high enough, because it may exists when the credit constraint is no more binding. Our result is also related to Hirano and Yanagawa (2017), who show in a model with heterogeneous productive investments that an intermediate degree of pledgeability is required for the existence of a bubble.

The bubble is productive if and only if $\bar{h}>\underline{h}$. This is equivalent to have $\bar{q}<\underline{q}$. Using (28) and (34), this means:

$$
F(\theta) \equiv \frac{\beta \theta(1-\theta)}{\theta(1+\beta)+\phi_{2} / \phi_{1}}<\left(\frac{\phi_{2}}{\phi_{1}}+1\right)\left[1-\frac{1-\alpha}{\alpha} \frac{\beta(1+\beta)}{1+\beta+\beta^{2}}\right]
$$

Note that the condition (40) holds if and only if condition (33) is satisfied. Therefore, the bubble is productive only when the bubbleless steady state is dynamically efficient and, hence, the bubble is used to raise investment. Condition (40) requires $\frac{\alpha}{1-\alpha}>\frac{\beta(1+\beta)}{1+\beta(1+\beta)}$, which implies $\theta^{*}>0$. It can be shown that $\frac{\phi_{1}+\phi_{2}}{\phi_{1}} \frac{\beta}{1+\beta+\beta^{2}}<\frac{\beta(1+\beta)}{1+\beta(1+\beta)}<\frac{\beta(1+2 \beta)}{1+\beta+\beta^{2}} \frac{\phi_{1}+\phi_{2}}{\phi_{1}+2 \phi_{2}}$ under $\phi_{2} / \phi_{1}<\beta$. Therefore, we focus on parameter configurations that satisfy:

$$
\frac{\beta(1+\beta)}{1+\beta(1+\beta)}<\frac{\alpha}{1-\alpha}<\frac{\beta(1+2 \beta)}{1+\beta+\beta^{2}} \frac{\phi_{1}+\phi_{2}}{\phi_{1}+2 \phi_{2}} .
$$

Our main result follows:

Proposition 4 If $\frac{\phi_{2}}{\phi_{1}}<\beta$ and $\frac{\alpha}{1-\alpha}$ is strictly lower but sufficiently close to $\frac{\beta(1+2 \beta)}{1+\beta+\beta^{2}} \frac{\phi_{1}+\phi_{2}}{\phi_{1}+2 \phi_{2}}$, we have:

1. The unconstrained bubbly steady state has a lower level of human capital than the constrained bubbleless steady state $(\bar{h}<\underline{h})$, i.e. the bubble is unproductive, if $\theta \in\left(\theta^{*}, \widehat{\theta}\right)$ 
2. The unconstrained bubbly steady state has a higher level of human capital than the constrained bubbleless steady state $(\bar{h}>\underline{h})$, i.e. the bubble is productive, if $\theta \in(\widehat{\theta}, \widetilde{\theta})$.

Proof. See Appendix A.3.

We observe that the bubble is productive only when $\frac{\alpha}{1-\alpha}>\frac{\beta(1+\beta)}{1+\beta(1+\beta)}$, which implies that $\bar{x}_{1}<0$. Since $\bar{x}_{1}+\bar{x}_{2}>0$, it means that $\bar{x}_{2}>0$. On the one hand, $\bar{x}_{1}<0$ implies that the bubble allows young agents to invest more in human capital by having a short position on the speculative asset. As a consequence, the bubble is beneficial for output, since output is larger than in the bubbleless steady state. It is the credit role of the bubble and corresponds to a crowdingin effect. It relaxes the credit constraint because borrowing through credit and short sale of the bubble is used by young individuals to increase investment in human capital.

On the other hand, $\bar{x}_{2}>0$ implies that middle age households finance the amount borrowed by the young and also generate the positive value of the bubble. This induces a crowding-out effect that fosters the economy to reach the golden rule, whose human capital stock is $\bar{h}$. This last effect, already identified in the seminal paper by Tirole (1985), has a negative impact on production but improves consumption since it allows to reach the golden rule. In fact, both the credit and the crowding-out effects imply a reallocation from middle age to young and old ages, since at middle age the household reimburses the amount borrowed when young and invests in the bubble to raise consumption when old. However, the bubble is productive when the crowding-in effect dominates the crowding-out one. This happens when $\theta$ is high enough, because the credit constraint is more easily relaxed, following an increase of human capital.

The demographic structure of overlapping generations play a key role because it introduces heterogeneous traders in the market, young and middle age agents. This heterogeneity explains that the bubble increases production. As young agents are short sellers of the speculative asset, they obtain the liquidity needed to raise productive investment.

It is worth mentioning that if $\frac{\alpha}{1-\alpha}<\frac{\beta(1+\beta)}{1+\beta(1+\beta)}$, we have $\bar{x}_{1} \geqslant 0$. Young agents do not borrow to raise human capital and production. In this case, condition (40) is not satisfied and we have $\bar{q}>\underline{q}$ and $\bar{h}<\underline{h}$. In other words, the existence of the bubble reduces human capital and production. In fact, when $\frac{\alpha}{1-\alpha}<\frac{\beta(1+\beta)}{1+\beta(1+\beta)}$ the credit constrained equilibrium without bubbles is inefficient and the only role played by the bubble is to crowd-out capital, as highlighted in Tirole (1985).

In this paper, we identify a new mechanism, based on the short sale of the bubble and the relaxed credit constraint, through which the bubble raises production, which is in accordance with the empirical evidence. This also means that if the bubble suddenly crashes, production will reduce, which is also in accordance with what we observe. These different facts are well documented by Caballero et al. (2006) and Martin and Ventura (2012), among others. 
As we have already mentioned, the parameter $\theta$ can be seen as a policy parameter that measures the financial regulation. The larger $\theta$ is, the more deregulated is the economy since a young trader is allowed to borrow more. To analyze the role of deregulation in our framework, we study more accurately the effect of the policy parameter $\theta$ on human capital. To this end, first note that $\bar{h}$ does not depend on $\theta$ (see equation (35)), whereas $\underline{h}$ varies with $\theta \cdot{ }^{14}$ Starting with a low value of $\theta$, an increase in this parameter has a direct effect through the credit constraint, increasing borrowing and investment. However, the interest rate $\underline{R}$ also increases, which deters borrowing and investment in human capital. Eventually, this second effect dominates and $\underline{h}$ decreases with $\theta$ for a sufficiently large $\theta$. This explains that when $\theta$ increases from $\theta^{*}$ to $\widetilde{\theta}$, we have first $\underline{h}>\bar{h}$. The difference between these two capital stocks first increases and, eventually, decreases. When $\theta$ crosses $\widehat{\theta}, \underline{h}=\bar{h}$, and $\underline{h}$ decreases and becomes lower than $\bar{h}$ for all $\theta \in(\widehat{\theta}, \tilde{\theta})$. Therefore, deregulation makes the bubble productive and, in fact, increases the difference between the two steady state stocks of human capital. However, more deregulation also means a larger loss of capital in the case of a crash of the bubble.

\section{Technological shocks}

Since illiquid human capital is a key ingredient of our results, we study in this section the effects on both the bubbly and bubbleless steady states of permanent technological shocks that affect the liquidity of human capital. These technological shocks consist on modifying the productivities $\phi_{1}$ or $\phi_{2}$. In this way, we can study the effect of a technological shock biased toward either short term return ( $\phi_{1}$ relative to $\phi_{2}$ increases) or a long term return $\left(\phi_{2}\right.$ relative to $\phi_{1}$ increases). Increasing $\phi_{1}$ and $\phi_{2}$ proportionally, we also investigate the case of a technological shock neutral with respect to the short versus long term returns of capital. We assume that we are in the most interesting configuration, where the constrained bubbleless and the unconstrained bubbly steady states coexist and the bubble is productive, and we analyze the effect of permanent technological shocks on long run human capital accumulation. We consider first the constrained bubbleless steady state.

Proposition 5 Assuming that $\frac{\phi_{2}}{\phi_{1}}<\beta, \widehat{\theta}<\theta<\widetilde{\theta}$ and $\frac{\alpha}{1-\alpha}$ strictly lower but sufficiently close to $\frac{\beta(1+2 \beta)}{1+\beta+\beta^{2}} \frac{\phi_{1}+\phi_{2}}{\phi_{1}+2 \phi_{2}}$, human capital $\underline{h}$ increases following an increase of either $\phi_{1}$ or $\phi_{1}$ and $\phi_{2}$ in the same proportion. When $\phi_{2}$ increases, the effect on $\underline{h}$ is undetermined.

Proof. See Appendix A.4.

${ }^{14}$ To see this, we combine (29) and (40), to obtain:

$$
\underline{h}=\frac{\alpha^{\frac{1}{1-\alpha}}}{\phi_{1}+\phi_{2}}\left[\frac{\beta(1+\beta)}{1+\beta+\beta^{2}}\left(\phi_{1}+\phi_{2}\right) \frac{1-\alpha}{\alpha}+\phi_{1} F(\theta)\right]^{\frac{1}{1-\alpha}}
$$


An increase of $\phi_{1}$ pushes up productive investment when young for two main reasons. First, it raises the return of human capital in middle age. Second, in the credit constrained steady state, it allows to borrow more when young to finance human capital investment. In contrast, an increase of $\phi_{2}$ has two opposite effects on human capital investment. A positive one because it raises the return of investment in old age. However, this increase of the return from human capital in old age incites a middle age household to save less, i.e. to finance less credit through a lower $x_{2}$. In the equilibrium without bubbles, the reduction of $x_{2}$ directly reduces borrowing ( $x_{1}$ less negative) and, therefore, decreases investment in human capital. Obviously, the interaction between these two opposite effects explains the ambiguous effect of $\phi_{2}$ on human capital accumulation.

We now focus on the unconstrained steady state with a positive bubble:

Proposition 6 Assuming that $\frac{\phi_{2}}{\phi_{1}}<\beta, \widehat{\theta}<\theta<\widetilde{\theta}$ and $\frac{\alpha}{1-\alpha}$ strictly lower but sufficiently close to $\frac{\beta(1+2 \beta)}{1+\beta+\beta^{2}} \frac{\phi_{1}+\phi_{2}}{\phi_{1}+2 \phi_{2}}$, we have the following:

1. Productive investment $\bar{h}$ increases, while the return $\bar{q}$ decreases if there is an increase of either $\phi_{1}$, or $\phi_{2}$ or of both, $\phi_{1}$ and $\phi_{2}$, in the same proportion;

2. $\bar{x}_{1}$ decreases if there is an increase of either $\phi_{1}$, or $\phi_{2}$ or of both, $\phi_{1}$ and $\phi_{2}$, in the same proportion;

3. $\bar{x}_{2}$ and $\bar{x}_{1}+\bar{x}_{2}$ increase if there is an increase of either $\phi_{1}$ or of both, $\phi_{1}$ and $\phi_{2}$, in the same proportion, but they decrease if there is an increase of $\phi_{2}$.

Proof. See Appendix A.5.

An increase of $\phi_{1}$ increases the incentive to invest in human capital when young. As a consequence, the investment in human capital and, hence, the amount borrowed by young households increases (lower $\bar{x}_{1}$ ). The middle age household has a larger income, even relatively to what she expects to have when old. Hence, she transfers a larger amount to old age, increasing her holding of the bubble $\bar{x}_{2}$. Despite the more significant short position of the young on the speculative asset, the value of the bubble, $\bar{x}_{1}+\bar{x}_{2}$, increases.

Following a raise of $\phi_{2}$, the difference between the returns of human capital and the bubble when old increases. Therefore, there is a substitution effect that pushes up productive investment, but pushes down the purchasing of the bubble $\bar{x}_{2}$ in middle age. To increase productive investment, young agents borrow more (lower $\bar{x}_{1}$ ). As both $\bar{x}_{1}$ and $\bar{x}_{2}$ decrease, the value of the bubble $\bar{x}_{1}+\bar{x}_{2}$ decreases.

When there is a proportional increase of $\phi_{1}$ and $\phi_{2}$, i.e. keeping $\phi_{2} / \phi_{1}$ constant, the technological shock is neutral. Of course, capital investment raises because its return through the life-cycle is greater. This increase is financed by increasing borrowing through the speculative asset (lower $\bar{x}_{1}$ ). Because the wage and the return from human capital in middle and old ages increase, there is no reallocation effect in the portfolio choices, but more significant positions of 
bubble holdings, meaning a higher $\bar{x}_{2}$. The value of the bubble $\bar{x}_{1}+\bar{x}_{2}$ increases, because it linearly depends on income.

In Proposition 6, we have enlightened how the bubbly steady state evolves according to various technological shocks. We have shown that while human capital increases with all the technological shocks considered, the value of the bubble may either increase or decrease, depending on the technological shock being biased toward long term, or rather toward short term or neutral. In addition, by direct inspection of Proposition 2, we see that the relative return of investment between the long and short terms $\phi_{2} / \phi_{1}$ affects the existence of the bubbly steady state and, therefore, its coexistence with the bubbleless one. We study now more deeply what is the effect of the different technological shocks on the existence of the bubbly steady state. This analysis is particularly important because we have assumed that $\frac{\alpha}{1-\alpha}$ is strictly lower but sufficiently close to $\frac{\beta(1+2 \beta)}{1+\beta+\beta^{2}} \frac{\phi_{1}+\phi_{2}}{\phi_{1}+2 \phi_{2}}$, which is the condition to have a positive bubble and, hence, small technological shocks may affect the existence of a bubble. To perform this analysis, note that $\bar{x}_{1}+\bar{x}_{2}>0$ is equivalent to $\phi_{2} / \phi_{1}<\Phi$, with:

$$
\Phi \equiv \frac{\frac{\beta+2 \beta^{2}}{1+\beta+\beta^{2}}-\frac{\alpha}{1-\alpha}}{2 \frac{\alpha}{1-\alpha}-\frac{\beta+2 \beta^{2}}{1+\beta+\beta^{2}}}
$$

Hence, $\Phi$ is strictly positive if:

Assumption $1 \frac{\beta(1+\beta)}{1+\beta+\beta^{2}}<\frac{\alpha}{1-\alpha}<\frac{\beta+2 \beta^{2}}{1+\beta+\beta^{2}}$.

We can also show that under $\frac{\alpha}{1-\alpha}>\frac{\beta(1+\beta)}{1+\beta(1+\beta)}, \Phi<\beta$. We then deduce the following proposition:

Proposition 7 Assuming $\phi_{2} / \phi_{1}<\beta, \widehat{\theta}<\theta<\widetilde{\theta}$ and that Assumption 1 holds, the bubbly steady state coexists with the bubbleless steady state for all $\phi_{2} / \phi_{1}<\Phi$, the bubble collapses for $\phi_{2} / \phi_{1}=\Phi$, and there is only the bubbleless steady state for $\phi_{2} / \phi_{1}>\Phi$. This means that:

1. Any permanent neutral technological shock that increases both $\phi_{1}$ and $\phi_{2}$ proportionally does not affect the existence of the bubbly steady state;

2. A permanent technological shock biased toward short term return that increases $\phi_{1}$ making $\phi_{1}>\phi_{2} / \Phi$ allows the existence of the bubbly steady state;

3. A permanent technological shock biased toward long term returns that increases $\phi_{2}$ making $\phi_{2}>\phi_{1} \Phi$ rules out the existence of the bubbly steady state.

There is a level of $\phi_{2} / \phi_{1}$ above which the bubbly steady state does no more exist and the only steady state is the bubbleless one. In contrast, for $\phi_{2} / \phi_{1}$ low enough, there is a multiplicity of steady states, the bubbleless one coexists with the bubbly one. Indeed, if $\phi_{2}$ is low regarding $\phi_{1}, h$ is more a short term 
investment because its return is larger in the first period than in the second one. In this case, middle age agents transfer wealth to the future by using the speculative asset. This explains the existence of the bubble, which allows to have a steady state where human capital investment benefits from the bubble liquidities. On the contrary, if $\phi_{2}$ is large regarding $\phi_{1}, h$ is more a long term investment because its return is larger in the second period. In this case, middle age agents do not use the bubble to transfer wealth to the future and there is no bubble liquidities to raise human capital investment. Therefore, technological shocks that raise the ratio $\phi_{2} / \phi_{1}$ may make the bubble crash.

Propositions 5-7 allow to have a general picture of long-run human capital following a permanent technological shock, biased toward short or long term returns, or which is neutral. Figure 1 illustrates the different cases. ${ }^{15}$ Panel (a) shows that if agents start by coordinating their expectations on the bubbly steady state and there is a technological shock that permanently raises $\phi_{2}$, productive investment $h$ increases if $\phi_{2}$ is low enough. Then, there is a level of $\phi_{2}$ above which the bubbly steady state disappears and productive investment may converge to the bubbleless steady state characterized by a lower level of $h$. When $\phi_{2}$ crosses the value such that the bubbly steady state disappears, we may observe a decrease of productive investment $h$ even if the technological shock increases its return in the long term. This means that a larger return in the long term does not necessarily imply higher levels of human capital. In this paper, the bubble provides liquidities to finance human capital, but a too significant return in the long-term rules out the bubble, and is therefore damaging for human capital itself.

Panel (b) of Figure 1 illustrates the opposite configuration, which happens when there is a technological shock that raises $\phi_{1}$. There is a threshold level above which the bubbly steady state exists. Then, if agents coordinate their expectations on the bubbly steady state, any further raise of the return $\phi_{1}$ implies a raise of capital. In addition, Proposition 7 allows us to argue that the bubble also enlarges under this type of technological shock.

Finally, if $\phi_{2} / \phi_{1}<\Phi$, a positive neutral technological shock has a similar effect on both steady states. This is shown in Panel $(c)$ of Figure 1. If agents coordinate their expectations on the bubbly steady state, such a technological shock induces a raise of capital and of the bubble size.

The last two results are especially interesting because they illustrate that in our model a permanent technological shock biased toward the short term or neutral between the short and the long terms is associated to larger levels of human capital, production and bubble size. These permanent positive shocks can be directly interpreted as innovations. Interestingly, there are many evidences showing that episodes of bubbles are often associated to new innovations (see for instance Caballero et al. (2006), Lansing (2008, 2012) and Scheinkman (2013)). ${ }^{16}$ Howitt and Aghion (1998) and Boucekkine et al. (2005b) among

\footnotetext{
${ }^{15}$ Note that Panel $(a)$ is drawn considering that $\underline{h}$ is increasing in $\phi_{2}$.

${ }^{16}$ Following Shiller (2000), Lansing (2008) relate four major run-ups in the real S\&P 500 stock index with the following technological advances: (i) In 1900s, the high speed rail travel, transatlantic radio and long-line electric transmission; (ii) In 1920s, mass production, travel
} 


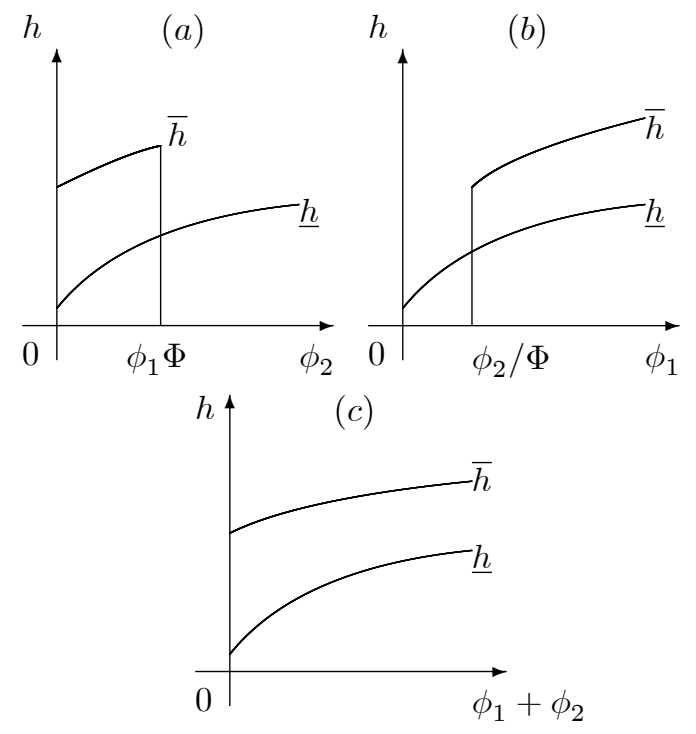

Figure 1: Effect of permanent technological shocks

many others have shown that innovations foster obsolescence. In the framework of this model, where human capital is formed by two groups of workers differentiated by age, and $\phi_{2}$ measures the productivity of the oldest group of workers, human capital obsolescence can be interpreted as a reduction of $\phi_{2}$ relative to $\phi_{1}$. Therefore, innovations may facilitate the emergence of bubbles according to the results in Proposition 7. As a consequence, this paper contributes to this literature by providing a rationale on the observed relation between periods of large innovations and episodes of bubbles. Finally, this result may also be related to Hirano and Yanagawa (2017) who consider a model with heterogenous investment projects. In their framework, a technological progress in favor of the most productive investment promotes the occurrence of bubbles.

Technological shocks that make the bubble disappear will govern dynamic paths that converge to the constrained bubbleless steady state with lower capital. We are not able to address analytically the analysis of dynamic transitions. However, they can be studied numerically. This is done in Figure 2, where we show the transitional dynamics due to a technological shock that permanently increases the ratio $\phi_{2} / \phi_{1} \cdot{ }^{17}$ The figure displays the transitional dynamics of

by roads and highways, commercial radio broadcast and widespread electrification of manufacturing; (iii) In 1950s and 1960s, television, suburban life style and space travel; (iv) In late $1990 \mathrm{~s}$, internet, innovations in computers and information technology, and emergence of the web-based business model.

${ }^{17}$ The value of the parameters in this numerical example are the following: $\alpha=0.4275$, $\beta=0.9$, and $\theta=0.164$. Regarding the technological parameters, before the shock they are $\phi_{1}=1.5$ and $\phi_{2}=0.0875$ and after the shock $\phi_{1}=1$ and $\phi_{2}=0.35$. These changes in the parameters are aimed to increase the ratio $\phi_{2} / \phi_{1}$, which makes the bubble disappear, while 
an economy that is initially in an unconstrained bubbly steady state and, after the shock that occurs in period 3, converges to a constraint bubbleless steady state. Panel $(a)$ shows that following the shock the amount borrowed by young individuals to finance human capital investment decreases (larger $x_{1}$ ). This is a consequence that, after the crash of the bubble, the economy is credit constrained, which limits the amount borrowed and, hence, reduces human capital investment. In fact, Panel (b) shows that human capital decreases during the transition. Panel $(c)$ shows that $q$ increases, which is a direct consequence of the reduction in human capital and Panel $(d)$ shows that the return from debt, $R_{t+1}$, is smaller than one along the entire transition in the credit constrained economy.

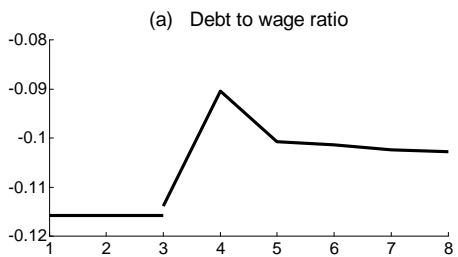

(c) $\mathrm{q}$

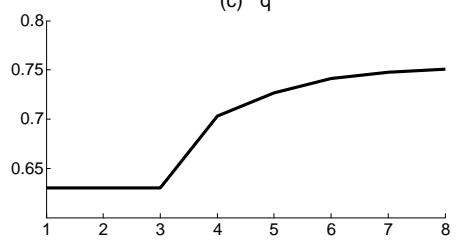

(b) Capital

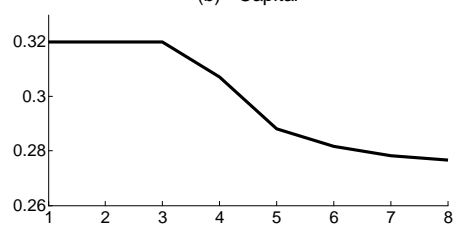

(d) Rt+1

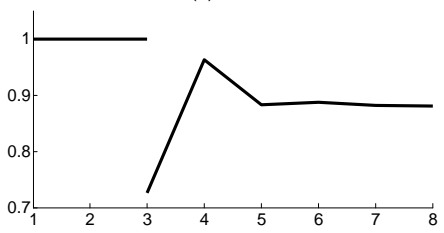

Figure 2. Transitional dynamics after a permanent technological shock.

\section{$5 \quad$ Fiscal policy}

There is a debate on the design of the fiscal policy that aims to promote long term investments (Wehinger (2011)). The purpose of this section is to contribute to this debate by studying the effect of taxes on both the existence of bubbles and on the stationary values of human capital. To this end, we consider a government that collects taxes on labor income, $\tau_{w}<1$, and on human capital income, $\tau_{h}<1$. As we interpret productive capital as human capital, $\tau_{h}$ must be interpreted as the tax rate on large wages, as large wages are typically obtained by high skilled workers. In this context, the labor income tax, $\tau_{w}$, must be interpreted as a tax on the wage of unskilled workers. Obviously, in a progressive tax system, $\tau_{w}<\tau_{h}$. We do not introduce a tax on the return of the speculative asset, nor on the return of the credit. On the one hand, the net return of the speculative asset is zero at a bubbly steady state and, thus, such a tax would be

they guarantee that the bubbly equilibrium is unconstrained, and the bubbeless equilibrium is credit constrained along the entire transition. 
irrelevant in the long run. On the other hand, we study steady states without bubbles that are credit constrained. As we have seen before, in this steady state, the net return of the credit is negative because $\underline{R}<1$ and, hence, the tax on the return of the credit is also irrelevant.

We assume that government revenues are employed to finance non-productive government spending $G_{t}$. In this way, government spending does not distort individuals decisions. At each period, the government budget is balanced:

$$
G_{t}=\tau_{w} w_{t}+\tau_{h} q_{t}\left(\phi_{1} h_{t}+\phi_{2} h_{t-1}\right)
$$

Note that if either $\tau_{w}<0$ or $\tau_{h}<0$, there is a subsidy on either labor or human capital. Such a policy scheme is in accordance with the government budget constraint, as long as $G_{t} \geqslant 0$.

The introduction of this fiscal policy modifies the individual budget constraints as follows:

$$
\begin{gathered}
c_{1, t}+h_{t+1}+x_{1, t}=\left(1-\tau_{w}\right) w_{t} \\
c_{2, t+1}+x_{2, t+1}=\left(1-\tau_{h}\right) \phi_{1} q_{t+1} h_{t+1}+R_{t+1} x_{1, t} \\
c_{3, t+2}=\left(1-\tau_{h}\right) \phi_{2} q_{t+2} h_{t+1}+R_{t+2} x_{2, t+1}
\end{gathered}
$$

and the credit constraint becomes

$$
R_{t+1} x_{1, t} \geq-\theta\left(1-\tau_{h}\right) q_{t+1} \phi_{1} h_{t+1}
$$

We study now how taxes modify the long run equilibrium with and without bubble. We examine in particular which type of fiscal policy promotes human capital accumulation.

To prove the existence of both the constrained bubbleless and the unconstrained bubbly steady states and compare them, we use the same methodology than in Section 3.

\subsection{Constrained bubbleless steady state with taxation}

Without bubble $\left(x_{1, t}+x_{2, t}=0\right)$, the solution of the consumer's problem when the utility function is (1), the budget constraints are (43), (44) and (45) and the credit constraint (46) is binding is characterized by the following first order conditions:

$$
\begin{aligned}
c_{3, t+2} & =R_{t+2} \beta c_{2, t+1} \\
c_{2, t+1}\left(\frac{1}{1-\tau_{h}}-\frac{\theta \phi_{1} q_{t+1}}{R_{t+1}}\right) & =\beta c_{1, t}\left(\phi_{1} q_{t+1}(1-\theta)+\frac{\phi_{2} q_{t+2}}{R_{t+2}}\right)
\end{aligned}
$$

and

$$
c_{2, t+1}>R_{t+1} \beta c_{1, t}
$$

We take into account that in the bubbleless steady state $x_{2}=-x_{1}$ and we substitute (44)-(46) in (47) to obtain the steady state return from the credit:

$$
R=\frac{\phi_{2}+\theta(1+\beta) \phi_{1}}{(1-\theta) \beta \phi_{1}} \equiv \underline{R}^{T}
$$


We proceed to obtain the steady state value of $q$. We substitute (43), (44) and (46) in (48) and use $w=\left(\phi_{1}+\phi_{2}\right) q h(1-\alpha) / \alpha$ to obtain:

$$
\begin{aligned}
& {\left[\phi_{1}-\frac{1+R}{R} \theta \phi_{1}\right]\left(\frac{1}{1-\tau_{h}}-\frac{\theta \phi_{1} q}{R}\right) } \\
= & \beta\left[\frac{\left(1-\tau_{w}\right)}{\left(1-\tau_{h}\right)} \frac{1-\alpha}{\alpha}\left(\phi_{1}+\phi_{2}\right) q-\frac{1}{1-\tau_{h}}+\frac{\theta q \phi_{1}}{R}\right]\left(\phi_{1}(1-\theta)+\frac{\phi_{2}}{R}\right)
\end{aligned}
$$

Using the steady state interest rate, we get:

$$
q=\frac{1}{\left(1-\tau_{w}\right) \frac{1-\alpha}{\alpha}\left(\phi_{1}+\phi_{2}\right)\left(\frac{(1+\beta) \beta}{1+\beta+\beta^{2}}\right)+\left(1-\tau_{h}\right)\left(\frac{\theta \phi_{1}(1-\theta) \beta \phi_{1}}{\phi_{2}+\theta(1+\beta) \phi_{1}}\right)} \equiv \underline{q}^{T}
$$

and using (18)-(20), we deduce that:

$$
\begin{aligned}
h & =\left(\frac{\alpha}{\underline{q}^{T}}\right)^{\frac{1}{1-\alpha}}\left(\frac{1}{\phi_{1}+\phi_{2}}\right) \equiv \underline{h}^{T} \\
w & =(1-\alpha)\left(\frac{\alpha}{\underline{q}^{T}}\right)^{\frac{\alpha}{1-\alpha}} \equiv \underline{w}^{T}
\end{aligned}
$$

Note that both taxes increase $q$ and reduce human capital. On the one hand, the tax on labor income reduces the net income available to invest in human capital. On the other hand, the tax on human capital reduces the collateral and, hence, it reduces investment in human capital as the credit constraint is binding.

Finally, this steady state is constrained if $c_{2}>\beta R c_{1}$, which occurs when $\underline{R}^{T}<1$, i.e. $\theta<\bar{\theta}$ and $\phi_{2} / \phi_{1}<\beta$, and:

$$
1-\frac{\theta \phi_{1}(1+\beta)+\phi_{2}}{\theta \phi_{1}+\phi_{2}} \frac{\beta}{1+\beta+\beta^{2}} \frac{\phi_{1}+\phi_{2}}{\phi_{1}} \frac{1-\alpha}{\alpha \Delta}>\theta
$$

where $\Delta \equiv \frac{1-\tau_{h}}{1-\tau_{w}}$ measures the asymmetric effect of taxes on the different sources of income. The left-hand side is decreasing in $\theta$ and strictly smaller than 1 , whereas the right-hand side is of course linearly increasing in $\theta$. Hence, there exist a $\tilde{\theta}^{T}<1$ such that the previous inequality holds if $\theta<\widetilde{\theta}^{T}$ and

$$
\Delta \frac{\alpha}{1-\alpha}>\frac{\phi_{1}+\phi_{2}}{\phi_{1}} \frac{\beta}{1+\beta+\beta^{2}}
$$

Proposition 8 There is a unique constrained bubbleless steady state with taxation $\underline{h}^{T}$ if:

1. $\theta<\min \left\{\bar{\theta}, \widetilde{\theta}^{T}\right\}$

2. $\phi_{2} / \phi_{1}<\beta$;

3. $\Delta \frac{\alpha}{1-\alpha}>\frac{\phi_{1}+\phi_{2}}{\phi_{1}} \frac{\beta}{1+\beta+\beta^{2}}$. 
Finally, we note that $\bar{\theta}>\widetilde{\theta}^{T}$ if and only if

$$
\Delta \frac{\alpha}{1-\alpha}<\frac{\phi_{1}+\phi_{2}}{2 \phi_{2}+\phi_{1}} \frac{\beta+2 \beta^{2}}{1+\beta+\beta^{2}}
$$

Note that the former proposition is a direct extension of Proposition 1, modified to include the taxes. It shows that fiscal policy has no effect on the existence of the constrained bubbleless steady state if $\tau_{w}=\tau_{h}$. Thus, only through asymmetric taxation of the two sources of income, fiscal policy can affect the existence of this equilibrium. In particular, this steady state exists when $\Delta$ is large and, hence, either $\tau_{h}$ is small or $\tau_{w}$ is large. When $\tau_{h}$ is small, the return after taxes of investment is large and, thus, individuals borrow until the constraint binds to increase investment. When $\tau_{w}$ is large, the wage after taxes is small, which limits investment in human capital. Individuals are forced to borrow until the constraint binds to invest in human capital.

\subsection{Unconstrained bubbly steady state with taxation}

Maximizing the utility (1) under the budget constraints (43)-(45), we show that, at the bubbly equilibrium $\left(x_{1, t}+x_{2, t}>0\right)$, the consumer's optimal choices satisfy:

$$
\begin{gathered}
R_{t+1}=\left(1-\tau_{h}\right)\left(q_{t+1} \phi_{1}+\frac{q_{t+2} \phi_{2}}{R_{t+2}}\right) \\
c_{2, t+1}=\beta c_{1, t} R_{t+1} \\
c_{3, t+2}=\beta c_{2, t+1} R_{t+2}
\end{gathered}
$$

At the bubbly steady state, $R=1$. Then, the previous equations simplify to $c_{2}=\beta c_{1}, c_{3}=\beta^{2} c_{1}$ and:

$$
q=\frac{1}{\left(1-\tau_{h}\right)\left(\phi_{1}+\phi_{2}\right)} \equiv \bar{q}^{T}
$$

Using (18)-(20), we obtain that:

$$
\begin{aligned}
h & =\left[\left(1-\tau_{h}\right) \alpha\right]^{\frac{1}{1-\alpha}}\left(\phi_{1}+\phi_{2}\right)^{\frac{\alpha}{1-\alpha}} \equiv \bar{h}^{T} \\
w & =(1-\alpha)\left[\alpha\left(1-\tau_{h}\right)\left(\phi_{1}+\phi_{2}\right)\right]^{\frac{\alpha}{1-\alpha}} \equiv \bar{w}^{T}
\end{aligned}
$$

and using (43)-(45), we get:

$$
\begin{aligned}
x_{2} & =\left(\frac{\beta^{2}}{1+\beta+\beta^{2}}-\frac{\Delta \phi_{2}}{\phi_{2}+\phi_{1}} \frac{\alpha}{1-\alpha}\right)\left(1-\tau_{w}\right) \bar{w}^{T} \equiv \bar{x}_{2}^{T} \\
x_{1} & =\left(B-\frac{\alpha \Delta}{1-\alpha}\right)\left(1-\tau_{w}\right) \bar{w}^{T} \equiv \bar{x}_{1}^{T} \\
\bar{x}_{1}^{T}+\bar{x}_{2}^{T} & =\left(\frac{\beta+2 \beta^{2}}{1+\beta+\beta^{2}}-\frac{\alpha \Delta}{1-\alpha} \frac{\phi_{1}+2 \phi_{2}}{\phi_{1}+\phi_{2}}\right)\left(1-\tau_{w}\right) \bar{w}^{T}
\end{aligned}
$$


When $\Delta=1$, the two tax rates are identical. In this case, they do not affect the existence of the bubble, as follows from the expression of $\bar{x}_{1}^{T}+\bar{x}_{2}^{T}$. Thus, the existence of a bubble does not depend on the level of the two tax rates, but on the difference between them. More precisely, a bubble $\left(\bar{x}_{1}^{T}+\bar{x}_{2}^{T}>0\right)$ exists if:

$$
\Delta \frac{\alpha}{1-\alpha}<\frac{\phi_{1}+\phi_{2}}{2 \phi_{2}+\phi_{1}} \frac{\beta+2 \beta^{2}}{1+\beta+\beta^{2}}
$$

Moreover, a bubbly steady state is unconstrained if $R \bar{x}_{1}^{T}>-\theta\left(1-\tau_{h}\right) \bar{q}^{T} \bar{h}^{T}$. Substituting $\bar{x}_{1}^{T}, \bar{q}^{T}$ and $\bar{h}^{T}$ in this expression, we deduce that the credit constrained is not binding at this steady state if and only if:

$$
\theta>\left(1-\frac{B}{\Delta} \frac{1-\alpha}{\alpha}\right) \frac{\phi_{1}+\phi_{2}}{\phi_{1}} \equiv \theta^{* T}
$$

Proposition 9 There is a unique unconstrained bubbly steady state with taxation $\bar{h}^{T}$ if:

1. $\theta>\theta^{* T}$;

2. $\Delta \frac{\alpha}{1-\alpha}<\frac{\phi_{1}+\phi_{2}}{2 \phi_{2}+\phi_{1}} \frac{\beta+2 \beta^{2}}{1+\beta+\beta^{2}}$.

Note that this proposition is a direct modification of Proposition 2, aimed to include the effect of taxes on the existence of an unconstrained bubbly steady state. As a main insight, we show that the effect of taxes on the existence of this steady state does not depend on the level of the tax rates, but on the differences between the two tax rates, measured by the parameter $\Delta$. More precisely, the bubble exists if $\Delta$ is small, which requires that either $\tau_{h}$ is large or $\tau_{w}$ is small. When $\tau_{h}$ is large, fiscal policy introduces the incentives to invest in the bubble. When $\tau_{w}$ is small, wages after taxes are large, which limits the amount of borrowing needed to invest in human capital. This facilitates the existence of an unconstrained bubbly equilibrium.

\subsection{The effect of fiscal policy on the occurrence of a pro- ductive bubble}

We first examine the coexistence of the constrained bubbleless and the unconstrained bubbly steady states with taxation.

Proposition 10 The unconstrained bubbly steady state with taxation $\left(\bar{h}^{T}\right)$ and the constrained bubbleless steady state with taxation $\left(\underline{h}^{T}\right)$ coexist if the following conditions are satisfied:

1. $\frac{\phi_{2}}{\phi_{1}}<\beta$;

2. $\theta^{* T}<\theta<\widetilde{\theta}^{T}$; 


$$
\text { 3. } \frac{\phi_{1}+\phi_{2}}{\phi_{1}} \frac{\beta}{1+\beta+\beta^{2}}<\Delta \frac{\alpha}{1-\alpha}<\frac{\beta(1+2 \beta)}{1+\beta+\beta^{2}} \frac{\phi_{1}+\phi_{2}}{\phi_{1}+2 \phi_{2}} \text {. }
$$

Proof. See Appendix A.6.

We examine now whether the bubble is capital enhancing or productive. More precisely, $\bar{q}^{T}<\underline{q}^{T}$ and $\bar{h}^{T}>\underline{h}^{T}$ if and only if:

$$
F(\theta)<\frac{\phi_{1}+\phi_{2}}{\phi_{1}}\left(1-\frac{1-\alpha}{\alpha} \frac{1}{\Delta} \frac{\beta+\beta^{2}}{1+\beta+\beta^{2}}\right)
$$

where $F(\theta)$ is defined and has the same properties than in equation (40). The previous inequality and Proposition 10 imply that the existence of productive bubbles requires:

$$
\frac{\beta(1+\beta)}{1+\beta(1+\beta)}<\Delta \frac{\alpha}{1-\alpha}<\frac{\beta(1+2 \beta)}{1+\beta+\beta^{2}} \frac{\phi_{1}+\phi_{2}}{\phi_{1}+2 \phi_{2}}
$$

Using the same procedure than in Proposition 4, we show:

Proposition 11 If $\frac{\phi_{2}}{\phi_{1}}<\beta$ and $\Delta \frac{\alpha}{1-\alpha}$ is strictly lower but sufficiently close to $\frac{\beta(1+2 \beta)}{1+\beta+\beta^{2}} \frac{\phi_{1}+\phi_{2}}{\phi_{1}+2 \phi_{2}}$, we have:

1. The unconstrained bubbly steady state with taxation has a lower level of capital than the constrained bubbleless steady state with taxation $\bar{h}^{T}<$ $\left.\underline{h}^{T}\right)$, i.e. the bubble is unproductive, if $\theta \in\left(\theta^{* T}, \widehat{\theta}^{T}\right)$;

2. The unconstrained bubbly steady state with taxation has a higher level of capital than the constrained bubbleless steady state with taxation $\bar{h}^{T}>$ $\left.\underline{h}^{T}\right)$, i.e. the bubble is productive, if $\theta \in\left(\widehat{\theta}^{T}, \tilde{\theta}^{T}\right)$.

Proof. See Appendix A.7.

We note the following direct implications of this proposition. First, the bubble may only be productive if it is characterized by $\bar{x}_{1}^{T}<0$, because $\Delta \frac{\alpha}{1-\alpha}>$ $\frac{\beta(1+\beta)}{1+\beta(1+\beta)}$. Thus, the bubble is productive only when it is used to finance human capital investment. Second, using (50) and (54), we have:

$$
\frac{\underline{q}^{T}}{\bar{q}^{T}}=\frac{\Delta\left(\phi_{1}+\phi_{2}\right)}{\frac{1-\alpha}{\alpha}\left(\phi_{1}+\phi_{2}\right) \frac{(1+\beta) \beta}{1+\beta+\beta^{2}}+\Delta \frac{\theta \phi_{1}(1-\theta) \beta \phi_{1}}{\phi_{2}+\theta(1+\beta) \phi_{1}}}
$$

We deduce that the gap between $\bar{q}^{T}$ and $\underline{q}^{T}$ decreases with $\Delta$ and, hence, the gap between $\bar{h}^{T}$ and $\underline{h}^{T}$ increases with $\Delta$. Third, we can easily show that both $\theta^{* T}$ and $\widetilde{\theta}^{T}$ are increasing in $\Delta$, whereas $\widehat{\theta}^{T}$ is decreasing (because $F^{\prime}\left(\widehat{\theta}^{T}\right)<0$ ). This means that following an increase of $\Delta$, the interval to have an unproductive 
bubble $\left(\theta^{* T}, \widehat{\theta}^{T}\right)$ shrinks, while the one to have a productive one $\left(\widehat{\theta}^{T}, \widetilde{\theta}^{T}\right)$ enlarges. Therefore, given $\theta$, a higher $\Delta$ can allow a bubble to become productive.

The previous implications show that the productive role of the bubble is determined by the relative significance of the tax rate on human capital $\tau_{h}$ and on labor income $\tau_{w}$. The reason is quite immediate. As we have seen above, human capital at the bubbleless steady state is determined by the wage income and the amount of collateral, and therefore, decreases with both the labor and the capital tax rates. In contrast, the level of human capital at the bubbly steady state is determined by an arbitrage condition between the speculative asset and capital. This explains that human capital at the bubbly steady state is only affected by the capital tax rate. We understand from these two observations that the bubble is capital enhancing if $\Delta$ is large enough, i.e. the human capital tax rate is low enough and/or the labor tax rate is sufficiently large.

The fiscal policy parameter $\Delta$ determines the effect of fiscal policy on the existence of bubbles and its nature, productive or unproductive, and it also determines the existence of a constrained bubbleless steady state. On the one hand, we have shown that for intermediate values of $\Delta$, a productive bubble may arise because the after-tax return on human capital is not too large to rule out bubble holding in middle age and the after-tax wage is large enough to sustain a large enough investment in human capital when young and the purchase of the bubble in middle age. In this case, the bubble is used by the young to finance human capital and by the middle age to transfer wealth to the future. On the other hand, recall that if $\Delta$ is too large, there is no bubble in the economy.

From the previous analysis, we obtain two interesting insights for the fiscal policy design. First, decreasing capital taxation is not always an appropriate policy to boost productive investment. If the policy is already accommodating, it may rule out the bubble and eliminate a mean to finance human capital. Second, reducing the labor income tax may not be growth enhancing when there is already a bubble. In this case, this policy may change the nature of the bubble making it unproductive. We conclude that the suitable fiscal policy to promote high levels of human capital and, therefore, of GDP depends on the existence and nature of the bubble.

\section{Concluding remarks}

This paper analyzes the interplay between liquid speculative bubbles with returns in the short term and less liquid productive investments in human capital which give returns in a longer term. We introduce this temporal distinction using an overlapping generations model with three-period lived agents. Agents make a portfolio choice between investment in human capital that gives returns during two periods, credit and a bubble traded at each period of time. Agents investments are limited by a credit constraint, where human capital plays the role of collateral. Considering that the bubbleless economy is dynamically efficient and credit constrained, the bubble enhances production because young traders, who invest in human capital, are short sellers of the speculative asset 
and are no more constrained by the limit on credit, while middle age traders buy the bubble. As a direct implication, we analyze the effect of financial regulation through the credit constraint on the levels of capital and bubble.

Our framework allows us to discuss the effect of permanent technological shocks. Productivity shocks either biased toward the short term return or neutral with respect to the relative productivities of capital in the short and longer terms push up human capital investment, production and the bubble size. Given that these permanent shocks can be interpreted as innovations, this result explains the connection between periods of innovations and the raise of both production and bubbles, which is found in the empirical literature. However, we show that this connection does not happen if the technological shock mainly increases the productivity of capital in the long run.

Introducing fiscal policy, we precisely discuss the effects of taxation of human capital versus labor income on the level of human capital and the bubble size. We argue that a low fiscal pressure on human capital income relative to labor income can be bad for productive investments, as this fiscal policy may rule out the bubble.

\section{A Appendix A}

\section{A.1 Household's program}

Households maximize the utility (1) subject to (6)-(8) and the constraint (9). Let $\lambda_{t}$ be the Lagrangian multiplier associated to equation (9). Then, the first order conditions with respect to $x_{1, t}, x_{2, t+1}$ and $h_{t+1}$ are, respectively,

$$
\begin{gathered}
-u^{\prime}\left(c_{1, t}\right)+\beta u^{\prime}\left(c_{2, t+1}\right) R_{t+1}+\lambda_{t} R_{t+1}=0 \\
-\beta u^{\prime}\left(c_{2, t+1}\right)+\beta^{2} u^{\prime}\left(c_{3, t+2}\right) R_{t+2}=0 \\
-u^{\prime}\left(c_{1, t}\right)+\beta u^{\prime}\left(c_{2, t+1}\right) \phi_{1} q_{t+1}+\beta^{2} u^{\prime}\left(c_{3, t+2}\right) \phi_{2} q_{t+2}+\lambda_{t} \theta \phi_{1} q_{t+1}=0
\end{gathered}
$$

From (59), we obtain that $\lambda_{t}=u^{\prime}\left(c_{1, t}\right) / R_{t+1}-\beta u^{\prime}\left(c_{2, t+1}\right)$. Therefore, if $u^{\prime}\left(c_{1, t}\right) / R_{t+1}>\beta u^{\prime}\left(c_{2, t+1}\right)$, then $\lambda_{t}>0$ and the constraint is binding. Taking into account that $u\left(c_{j, t}\right)=\ln c_{j, t}$, the solution of the household's problem when the credit constraint is binding is given by equations (12)-(14).

If the credit constraint is not binding, we have $\lambda_{t}=0$ and the solution of the household's problem is given by equations (15)-(17).

\section{A.2 Proof of Proposition 3}

Using Proposition 1, we recall that there exists a constrained bubbleless steady state if $\theta<\min \{\bar{\theta}, \widetilde{\theta}\}, \phi_{2} / \phi_{1}<\beta$ and $\frac{\alpha}{1-\alpha}>\frac{\phi_{1}+\phi_{2}}{\phi_{1}} \frac{\beta}{1+\beta+\beta^{2}}$. Using Proposition 2 , there exists a unique unconstrained bubbly steady state if $\theta>\theta^{*}$ and $\frac{\alpha}{1-\alpha}<$ $\frac{\beta(1+2 \beta)}{1+\beta+\beta^{2}} \frac{\phi_{1}+\phi_{2}}{\phi_{1}+2 \phi_{2}}$. Using (30) and (39), we obtain that $\bar{\theta}>\theta^{*}$ if and only if $\frac{\alpha}{1-\alpha}<\frac{\beta(1+2 \beta)}{1+\beta+\beta^{2}} \frac{\phi_{1}+\phi_{2}}{\phi_{1}+2 \phi_{2}}$. Substituting $\theta^{*}$ in (31), we see that it holds as a strict 
inequality if and only if $\frac{\alpha}{1-\alpha}<\frac{\beta(1+2 \beta)}{1+\beta+\beta^{2}} \frac{\phi_{1}+\phi_{2}}{\phi_{1}+2 \phi_{2}}$. We deduce that, in this case, we have $\theta^{*}<\widetilde{\theta}$. Substituting (30) in (31), we see that this last inequality never holds under $\frac{\alpha}{1-\alpha}<\frac{\beta(1+2 \beta)}{1+\beta+\beta^{2}} \frac{\phi_{1}+\phi_{2}}{\phi_{1}+2 \phi_{2}}$, which means that $\bar{\theta}>\widetilde{\theta}$. Finally, we note that $\frac{\phi_{1}+\phi_{2}}{\phi_{1}} \frac{\beta}{1+\beta+\beta^{2}}<\frac{\beta(1+2 \beta)}{1+\beta+\beta^{2}} \frac{\phi_{1}+\phi_{2}}{\phi_{1}+2 \phi_{2}}$ is satisfied under $\phi_{2} / \phi_{1}<\beta$. The proposition immediately follows.

\section{A.3 Proof of Proposition 4}

In the main text, we show that $\bar{h}>\underline{h}$ if condition (40) holds. We can see that $F(\theta)$ is an inverse U-shaped concave function $\left(F(\theta)^{\prime \prime}<0\right)$ with $F(0)=F(1)=$ $0, F^{\prime}(0)>0$ and $F^{\prime}(1)<0$. Substituting $\theta^{*}$ in inequality (40), we can show that the inequality is not satisfied when $\frac{\alpha}{1-\alpha}<\frac{\beta(1+2 \beta)}{1+\beta+\beta^{2}} \frac{\phi_{1}+\phi_{2}}{\phi_{1}+2 \phi_{2}}$. Using (31), we get:

$$
\frac{\beta \widetilde{\theta}(1-\tilde{\theta})}{\widetilde{\theta}(1+\beta)+\phi_{2} / \phi_{1}}=\frac{\widetilde{\theta}\left(\phi_{1}+\phi_{2}\right)}{\widetilde{\theta} \phi_{1}+\phi_{2}} \frac{\beta^{2}}{1+\beta+\beta^{2}} \frac{1-\alpha}{\alpha}
$$

Using this expression, $F(\widetilde{\theta})<\left(\frac{\phi_{2}}{\phi_{1}}+1\right)\left[1-\frac{1-\alpha}{\alpha} \frac{\beta(1+\beta)}{1+\beta+\beta^{2}}\right]$ is equivalent to:

$$
\frac{\alpha}{1-\alpha}>\frac{\beta\left(\widetilde{\theta} \phi_{1}+\phi_{2}\right)+\beta^{2}\left(2 \tilde{\theta} \phi_{1}+\phi_{2}\right)}{\left(1+\beta+\beta^{2}\right)\left(\widetilde{\theta} \phi_{1}+\phi_{2}\right)}
$$

In addition,

$$
\frac{\beta\left(\widetilde{\theta} \phi_{1}+\phi_{2}\right)+\beta^{2}\left(2 \widetilde{\theta} \phi_{1}+\phi_{2}\right)}{\left(1+\beta+\beta^{2}\right)\left(\widetilde{\theta} \phi_{1}+\phi_{2}\right)}<\frac{\beta(1+2 \beta)}{1+\beta+\beta^{2}} \frac{\phi_{1}+\phi_{2}}{\phi_{1}+2 \phi_{2}}
$$

is equivalent to $\widetilde{\theta}<\bar{\theta}$, which is satisfied, as shown in the proof of Proposition 3. This means that for $\frac{\alpha}{1-\alpha}$ lower but sufficiently close to $\frac{\beta(1+2 \beta)}{1+\beta+\beta^{2}} \frac{\phi_{1}+\phi_{2}}{\phi_{1}+2 \phi_{2}}, \widetilde{\theta}$ satisfies inequality (40). Therefore, there exists a unique $\widehat{\theta} \in\left(\theta^{*}, \widetilde{\theta}\right)$ such that:

$$
F(\widehat{\theta})=\left(\frac{\phi_{2}}{\phi_{1}}+1\right)\left[1-\frac{1-\alpha}{\alpha} \frac{\beta(1+\beta)}{1+\beta+\beta^{2}}\right]
$$

We deduce that inequality (40) is satisfied for all $\theta \in(\widehat{\theta}, \widetilde{\theta})$ and it is not satisfied for $\theta \in\left(\theta^{*}, \widehat{\theta}\right)$, which proves the results of Proposition 4.

\section{A.4 Proof of Proposition 5}

From (28) and (29), we obtain

$$
\underline{h}=\frac{\alpha^{\frac{1}{1-\alpha}}}{\phi_{1}+\phi_{2}}\left[\frac{\beta(1+\beta)}{1+\beta+\beta^{2}}\left(\phi_{1}+\phi_{2}\right) \frac{1-\alpha}{\alpha}+\frac{\phi_{1}^{2} \beta(1-\theta) \theta}{\theta \phi_{1}(1+\beta)+\phi_{2}}\right]^{\frac{1}{1-\alpha}}
$$


Differentiating this equation with respect to $\phi_{1}$, we obtain:

$$
\begin{aligned}
& \frac{\partial \underline{h}}{\partial \phi_{1}} \frac{\phi_{1}}{\underline{h}}\left[\frac{\beta(1+\beta)}{1+\beta+\beta^{2}}\left(\phi_{1}+\phi_{2}\right) \frac{1-\alpha}{\alpha}+\frac{\phi_{1}^{2} \beta(1-\theta) \theta}{\theta \phi_{1}(1+\beta)+\phi_{2}}\right]=\frac{\beta(1+\beta)}{1+\beta+\beta^{2}} \phi_{1} \\
& +\frac{\phi_{1}^{2} \beta(1-\theta) \theta\left[\theta \phi_{1}(1+\beta)+2 \phi_{2}-(1-\alpha) \frac{\phi_{1}}{\phi_{1}+\phi_{2}}\left(\theta \phi_{1}(1+\beta)+\phi_{2}\right)\right]}{(1-\alpha)\left[\theta \phi_{1}(1+\beta)+\phi_{2}\right]^{2}}>0
\end{aligned}
$$

Now, let $\phi_{2}=\bar{a} \phi_{1}$, with $\bar{a}$ a positive constant. Substituting this expression of $\phi_{2}$ in (65), we easily get:

$$
\left.\frac{\partial \underline{h}}{\partial \phi_{1}} \frac{\phi_{1}}{\underline{h}}\right|_{\phi_{2}=\bar{a} \phi_{1}}=\frac{\alpha}{1-\alpha}>0
$$

Finally,

$$
\begin{aligned}
& \frac{\partial \underline{h}}{\partial \phi_{2}} \frac{\phi_{2}}{\underline{h}}\left[\frac{\beta(1+\beta)}{1+\beta+\beta^{2}}\left(\phi_{1}+\phi_{2}\right) \frac{1-\alpha}{\alpha}+\frac{\phi_{1}^{2} \beta(1-\theta) \theta}{\theta \phi_{1}(1+\beta)+\phi_{2}}\right]=\frac{\beta(1+\beta)}{1+\beta+\beta^{2}} \phi_{2} \\
& -\frac{\phi_{1}^{2} \phi_{2} \beta(1-\theta) \theta}{(1-\alpha)\left[\theta \phi_{1}(1+\beta)+\phi_{2}\right]^{2}}\left[1+\frac{1-\alpha}{\phi_{1}+\phi_{2}}\left(\theta \phi_{1}(1+\beta)+\phi_{2}\right)\right]
\end{aligned}
$$

which has an undetermined sign under the assumptions $\frac{\phi_{2}}{\phi_{1}}<\beta, \widehat{\theta}<\theta<\widetilde{\theta}$ and $\frac{\alpha}{1-\alpha}$ strictly lower but sufficiently close to $\frac{\beta(1+2 \beta)}{1+\beta+\beta^{2}} \frac{\phi_{1}+\phi_{2}}{\phi_{1}+2 \phi_{2}}$.

\section{A.5 Proof of Proposition 6}

From (34) and (35) we deduce that $\partial \bar{q} / \partial \phi_{1}<0, \partial \bar{h} / \partial \phi_{1}>0, \partial \bar{q} / \partial \phi_{2}<0$, $\partial \bar{h} / \partial \phi_{2}>0$ and, taking $\phi_{2} / \phi_{1}$ constant, $\partial \bar{q} / \partial\left(\phi_{1}+\phi_{2}\right)<0$ and $\partial \bar{h} / \partial\left(\phi_{1}+\phi_{2}\right)>$ 0 .

We now focus on the bubble size and speculative asset holdings. The wage is given by $\bar{w}=(1-\alpha) \alpha^{\frac{\alpha}{1-\alpha}}\left(\phi_{1}+\phi_{2}\right)^{\frac{\alpha}{1-\alpha}}$. Therefore, using (37) and inequality (41), we easily deduce that $\partial \bar{x}_{1} / \partial \phi_{1}<0, \partial \bar{x}_{1} / \partial \phi_{2}<0$ and, taking $\phi_{2} / \phi_{1}$ constant, $\partial \bar{x}_{1} / \partial\left(\phi_{1}+\phi_{2}\right)<0$.

Note that $\phi_{2} /\left(\phi_{2}+\phi_{1}\right)$ is decreasing in $\phi_{1}$ and does not vary when $\phi_{2} / \phi_{1}$ stays constant. Note also that inequality (41) implies that $x_{1}<0$ and, hence, $x_{2}>0$. Then, by direct inspection of (36), we get $\partial \bar{x}_{2} / \partial \phi_{1}>0$ and, taking $\phi_{2} / \phi_{1}$ constant, $\partial \bar{x}_{2} / \partial\left(\phi_{1}+\phi_{2}\right)>0$. Substituting the expression of the wage in (36), we also get:

$$
\frac{\partial \bar{x}_{2}}{\partial \phi_{2}}=\alpha^{\frac{1}{1-\alpha}}\left(\phi_{1}+\phi_{2}\right)^{\frac{2 \alpha-1}{1-\alpha}}\left(\frac{\phi_{2}}{\phi_{1}+\phi_{2}} \frac{1-2 \alpha}{1-\alpha}-\frac{1+\beta}{1+\beta+\beta^{2}}\right)
$$

This is strictly negative if and only if

$$
(1-\alpha)(1+\beta)>\left[(1-2 \alpha) \beta^{2}-\alpha(1+\beta)\right]\left(\frac{\phi_{2}}{\phi_{1}}\right)
$$


This last inequality is satisfied for all $\phi_{2} / \phi_{1}>0$ if its right-hand side is negative. It requires:

$$
\frac{\alpha}{1-\alpha}>\frac{\beta^{2}}{1+\beta+\beta^{2}}
$$

Since this is always satisfied under inequality (41), we have $\partial \bar{x}_{2} / \partial \phi_{2}<0$.

Using all these results, we obviously have $\partial\left(\bar{x}_{1}+\bar{x}_{2}\right) / \partial \phi_{2}<0$. Let us note that $\left(2 \phi_{2}+\phi_{1}\right) /\left(\phi_{2}+\phi_{1}\right)$ decreases with respect to $\phi_{1}$ and does not vary when $\phi_{2} / \phi_{1}$ stays constant. Using (38), we deduce that $\partial\left(\bar{x}_{1}+\bar{x}_{2}\right) / \partial \phi_{1}>0$ and, taking $\phi_{2} / \phi_{1}$ constant, $\partial\left(\bar{x}_{1}+\bar{x}_{2}\right) / \partial\left(\phi_{1}+\phi_{2}\right)>0$.

\section{A.6 Proof of Proposition 10}

First, note that we have $\frac{\phi_{1}+\phi_{2}}{2 \phi_{2}+\phi_{1}} \frac{\beta+2 \beta^{2}}{1+\beta+\beta^{2}}>\frac{\phi_{1}+\phi_{2}}{\phi_{1}} \frac{\beta}{1+\beta+\beta^{2}}$ for $\phi_{2} / \phi_{1}<\beta$. We also have $\theta^{* T}<\tilde{\theta}^{T}<\bar{\theta}$ for $\Delta \frac{\alpha}{1-\alpha}<\frac{\phi_{1}+\phi_{2}}{2 \phi_{2}+\phi_{1}} \frac{\beta+2 \beta^{2}}{1+\beta+\beta^{2}}$. We can then prove the results in Proposition 10 from the analysis in Section 3.

\section{A.7 Proof of Proposition 11}

We can show that for $\theta=\theta^{* T}$, inequality (57) is not satisfied under $\Delta \frac{\alpha}{1-\alpha}<$ $\frac{\beta(1+2 \beta)}{1+\beta+\beta^{2}} \frac{\phi_{1}+\phi_{2}}{\phi_{1}+2 \phi_{2}}$. Moreover, using (51), we have:

$$
F\left(\widetilde{\theta}^{T}\right)=\frac{1}{\Delta} \frac{\tilde{\theta}^{T}\left(\phi_{1}+\phi_{2}\right)}{\phi_{2}+\widetilde{\theta}^{T} \phi_{1}} \frac{1-\alpha}{\alpha} \frac{\beta^{2}}{1+\beta+\beta^{2}}
$$

We deduce that $F\left(\widetilde{\theta}^{T}\right)$ satisfies inequality (57) if and only if:

$$
\Delta \frac{\alpha}{1-\alpha}>\frac{\beta\left(\phi_{2}+\tilde{\theta}^{T} \phi_{1}\right)+\beta^{2}\left(\phi_{2}+2 \tilde{\theta}^{T} \phi_{1}\right)}{\left(\phi_{2}+\widetilde{\theta}^{T} \phi_{1}\right)\left(1+\beta+\beta^{2}\right)}
$$

Then, there exists $\widehat{\theta}^{T} \in\left(\theta^{* T}, \widetilde{\theta}^{T}\right)$ such that inequality (57) is not satisfied for $\theta \in\left(\theta^{* T}, \widehat{\theta}^{T}\right)$, but is satisfied for $\theta \in\left(\widehat{\theta}^{T}, \tilde{\theta}^{T}\right)$. We also note that the right-hand side of this inequality is strictly lower than $\frac{\beta(1+2 \beta)}{1+\beta+\beta^{2}} \frac{\phi_{1}+\phi_{2}}{\phi_{1}+2 \phi_{2}}$ because $\tilde{\theta}^{T}<\bar{\theta}$. This proves Proposition 11. 


\section{B Appendix B}

\section{B.1 Constrained bubbly steady state}

The market clearing condition (11) implies that $\bar{R}^{c}=1$. From the first order conditions (12)-(14) and the budget constraints, we get:

$$
\begin{aligned}
h & =\left(\frac{1}{\phi_{1}+\phi_{2}}\right)\left(\frac{\bar{q}^{c}}{\alpha}\right)^{\frac{1}{\alpha-1}} \equiv \bar{h}^{c} \\
q & =\frac{1}{\left(\frac{1-\alpha}{\alpha}\right)\left(\phi_{1}+\phi_{2}\right) \frac{(1+\beta) \beta}{1+\beta(1+\beta)}+\theta \phi_{1}} \equiv \bar{q}^{c}
\end{aligned}
$$

and

$$
\begin{aligned}
x_{1} & =-\theta \phi_{1} \bar{q}^{c} \bar{h}^{c} \equiv \bar{x}_{1}^{c} \\
x_{2} & =\left[\frac{\beta(1-\theta) \phi_{1}-\phi_{2}}{1+\beta}\right] \bar{h}^{c} \bar{q}^{c} \equiv \bar{x}_{2}^{c} \\
\bar{x}_{2}^{c}+\bar{x}_{1}^{c} & =\left[\frac{[\beta-\theta(1+2 \beta)] \phi_{1}-\phi_{2}}{1+\beta}\right] \bar{q}^{c} \bar{h}^{c}
\end{aligned}
$$

We deduce that there is a positive bubble $\bar{x}_{2}^{c}+\bar{x}_{1}^{c}>0$ if and only if $\theta<\bar{\theta}$ and $\phi_{2} / \phi_{1}<\beta$, where $\bar{\theta}$ is given by (30).

The credit constraint is binding if $c_{2, t+1}>\beta R_{t+1} c_{1, t}$. At a bubbly steady state, this condition holds if

$$
\theta<\frac{\phi_{1}+\phi_{2}}{\phi_{1}}\left[1-\left(\frac{1-\alpha}{\alpha}\right)\left(\frac{\beta(1+\beta)}{1+\beta(1+\beta)}\right)\right] \equiv \theta^{*}
$$

that requires $\frac{\alpha}{1-\alpha}>\frac{\beta(1+\beta)}{1+\beta(1+\beta)}$.

Proposition 12 There is a unique constrained bubbly steady state $\bar{h}$ if:
1. $\theta<\min \left\{\bar{\theta}, \theta^{*}\right\}$;
2. $\phi_{2} / \phi_{1}<\beta$;
3. $\frac{\alpha}{1-\alpha}>\frac{\beta(1+\beta)}{1+\beta(1+\beta)}$.

We next show that the bubble cannot be productive when both bubbleless and bubbly steady states are constrained. We claim that a bubble is productive if $\bar{h}^{c}>\underline{h}$ or, equivalently, $\bar{q}^{c}<\underline{q}$. Using (28) and (69), we get that the bubble is productive if $\theta>\bar{\theta}$. This contradicts the existence of a positive bubble. Using Propositions 1 and 12, we deduce that:

Proposition 13 The constrained bubbly $\left(\bar{h}^{c}\right)$ and bubbleless ( $\left.\underline{h}\right)$ steady states coexist if: 
1. $\theta<\min \left\{\bar{\theta}, \widetilde{\theta}, \theta^{*}\right\}$

2. $\phi_{2} / \phi_{1}<\beta$;

3. $\frac{\alpha}{1-\alpha}>\max \left\{\frac{\beta(1+\beta)}{1+\beta+\beta^{2}} ; \frac{\phi_{1}+\phi_{2}}{\phi_{1}} \frac{\beta}{1+\beta+\beta^{2}}\right\}$.

In addition, we have $\bar{h}^{c}<\underline{h}$.

\section{B.2 Positive probability of bubble crash}

We aim to understand whether our results still hold when there is a positive probability of market crash for the bubble. To this end, we extend our framework to the case where the bubble is stochastic. When there is a bubble, agents may coordinate their expectations on an equilibrium without bubble because of a sunspot process which associates a positive probability to a market crash. In such an economy, a stochastic bubbly steady state, i.e. a steady state with positive bubble that takes into account that the bubble may crash with a positive probability, will coexist with the bubbleless one examined in Section 3.

Following Weil (1987), we consider a Markov process of a bubble crash. If there is no bubble at period $t$, there is no bubble at period $t+1$ with a probability 1 . If there is a bubble at period $t$, there is a probability $\pi \in(0,1]$ such that the bubble persists at the next period and a probability $1-\pi$ such that the bubble crashes at period $t+1$. Note that a market crash in period $t+1$ means that the price $p_{t+1}$ of the asset without fundamental value is zero, i.e. $b_{1, t+1}=b_{2, t+1}=R_{t+1}=0$ using the notations of Section 2. In contrast, credit $d_{t+1}$ and its return $R_{t+1}^{d}$ remain positive, even if they are affected by the bubble crash.

Let us examine the household's behavior in such a stochastic environment. To fix ideas, we focus on a household born at period $t$ and we assume that there is a bubble at this date. ${ }^{18}$ In the following, we denote $c_{2, t+1}^{+}\left(c_{2, t+1}^{0}\right)$ the consumption in middle age when the bubble persists (crashes) in $t+1$. If the bubble crashes in $t+1$, the consumption when old is $c_{3, t+2}^{00}$. If the bubble does not crash in $t+1$, the consumption when old is $c_{3, t+2}^{++}$if it does not crash in $t+2$ too, while it is $c_{3, t+2}^{+0}$ if it crashes in $t+2$ (see also Figure 3 ).

Using (2)-(4), we deduce that the different household's consumptions are given by:

$$
\begin{aligned}
c_{1, t} & =w_{t}+d_{t}-h_{t+1}-b_{1, t}, \\
c_{2, t+1}^{+} & =\phi_{1} q_{t+1} h_{t+1}+R_{t+1} b_{1, t}-R_{t+1}^{d} d_{t}-b_{2, t+1}-d_{t+1}, \\
c_{2, t+1}^{0} & =\phi_{1} q_{t+1} h_{t+1}-R_{t+1}^{d} d_{t}-d_{t+1}^{0}, \\
c_{3, t+2}^{++} & =\phi_{2} q_{t+2} h_{t+1}+R_{t+2} b_{2, t+1}+R_{t+2}^{d} d_{t+1}, \\
c_{3, t+2}^{+0} & =\phi_{2} q_{t+2} h_{t+1}+R_{t+2}^{d} d_{t+1}, \\
c_{3, t+2}^{00} & =\phi_{2} q_{t+2}^{0} h_{t+1}+R_{t+2}^{d, 0} d_{t+1}^{0}
\end{aligned}
$$

${ }^{18}$ If there is no bubble at this period, one get the bubbleless economy. 


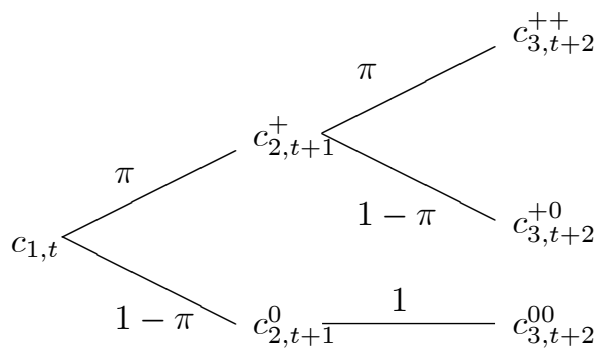

Figure 3: Consumption profile when the bubble has a probability to crash $1-\pi$

where variables without the zero as a superscript correspond to choice variables decided when there is a bubble and resulting prices. In contrast, $d_{t+1}^{0}$ is the choice of debt holding following a bubble crash. Moreover, even if human capital is a long term investment, $q_{t+2}^{0}$ in (78) is different from $q_{t+2}$ because it depends on $h_{t+2}^{0}$, which is the investment in human capital decided by a new generation after the bubble crash. Finally, $R_{t+2}^{d, 0}$ is the return of debt in the absence of bubble.

The household determines her choices maximizing her expected utility $\mathbb{E}_{t}\left[u\left(c_{1, t}\right)\right.$ $\left.+\beta u\left(c_{2, t+1}\right)+\beta^{2} u\left(c_{3, t+2}\right)\right]$, that rewrites:

$$
\begin{aligned}
& u\left(c_{1, t}\right)+\beta\left[\pi u\left(c_{2, t+1}^{+}\right)+(1-\pi) u\left(c_{2, t+1}^{0}\right)\right] \\
& +\beta^{2}\left[\pi^{2} u\left(c_{3, t+2}^{++}\right)+\pi(1-\pi) u\left(c_{3, t+2}^{+0}\right)+(1-\pi) u\left(c_{3, t+2}^{00}\right)\right]
\end{aligned}
$$

Maximizing (79) under the constraints (73)-(78) with respect to $b_{1, t}, b_{2, t+1}, d_{t}$, $d_{t+1}, d_{t+1}^{0}$ and $h_{t+1}$, we obtain:

$$
\begin{aligned}
\frac{1}{c_{1, t}}= & R_{t+1} \frac{\beta \pi}{c_{2, t+1}^{+}} \\
\frac{\beta \pi}{c_{2, t+1}^{+}}= & R_{t+2} \frac{\beta^{2} \pi^{2}}{c_{3, t+2}^{++}} \\
\frac{1}{c_{1, t}}= & R_{t+1}^{d}\left[\frac{\beta \pi}{c_{2, t+1}^{+}}+\frac{\beta(1-\pi)}{c_{2, t+1}^{0}}\right] \\
\frac{\beta \pi}{c_{2, t+1}^{+}}= & R_{t+2}^{d}\left[\frac{\beta^{2} \pi^{2}}{c_{3, t+2}^{++}}+\frac{\beta^{2} \pi(1-\pi)}{c_{3, t+2}^{+0}}\right] \\
\frac{\beta(1-\pi)}{c_{2, t+1}^{0}}= & R_{t+2}^{d, 0} \frac{\beta^{2}(1-\pi)}{c_{3, t+2}^{00}} \\
\frac{1}{c_{1, t}}= & \phi_{1} q_{t+1}\left[\frac{\beta \pi}{c_{2, t+1}^{+}}+\frac{\beta(1-\pi)}{c_{2, t+1}^{0}}\right]+\phi_{2} q_{t+2}^{0} \frac{\beta^{2}(1-\pi)}{c_{3, t+2}^{00}} \\
& +\phi_{2} q_{t+2}\left[\frac{\beta^{2} \pi^{2}}{c_{3, t+2}^{++}}+\frac{\beta^{2} \pi(1-\pi)}{c_{3, t+2}^{+0}}\right]
\end{aligned}
$$


where $R_{t+2}^{d, 0}=\underline{R}_{t+2}$. To be consistent with the analysis of Section 3 , the credit constraint should be binding when the bubble crashes, i.e. $d_{t+1}^{0}=$ $\theta \phi_{1} \underline{q}_{t+1} \underline{k}_{t+2} / \underline{R}_{t+2}$. Moreover, when the bubble is positively valued at period $t$, the credit constraint should not be binding, i.e. $R_{t+1}^{d} d_{t}<\theta \phi_{1} q_{t+1} k_{t+1}+$ $R_{t+1} b_{1, t}$.

The first order conditions (80)-(85) and the budget constraints (73)-(78) can be used with the prices (19)-(20) and the equilibrium conditions on the asset markets to determine a stochastic bubbly equilibrium. When $\pi$ is equal to 1 , equations (80)-(85) are equivalent to the first order conditions without bubble crash (59)-(61) (with $\lambda_{t}=0$ ), which means that the allocation corresponds to the deterministic bubbly equilibrium. By continuity with respect to $\pi$, the equilibrium will still exist when $\pi$ is smaller but sufficiently close to 1 . This is especially true when we focus on the stationary allocations, as in Section 3. This is similar to what we can find in the seminal paper by Weil (1987), and many more recent papers like Fahri and Tirole (2012), Hirano and Yanagawa (2017) or Kocherlakota (2009). Since the introduction of a positive probability of bubble burst will not bring any new ingredient for our explanation of productive bubble at the cost of strong additional complexities, we do not explicitly solve the stochastic model for the sake of conciseness.

\section{References}

[1] Abel, A. B., N. G. Mankiw, L. H. Summers and R. J. Zeckhauser (1989): "Assessing dynamic efficiency: theory and evidence," Review of Economic Studies 56, 1-19.

[2] Benhabib, J. and A. Rustichini (1991): "Vintage capital, investment and growth", Journal of Economic Theory 55, 323-339.

[3] Bosi, S. and T. Seegmuller (2010): "On rational exuberance", Mathematical Social Sciences 59, 249-270.

[4] Boucekkine, R., O. Licandro, L. A. Puch and F. del Rio (2005a): "Vintage capital and the dynamics of the AK model", Journal of Economic Theory 120, 39-72.

[5] Boucekkine, R., F. del Rio and O. Licandro (2005b): "Obsolescence and modernization in the growth process", Journal of Development Economics 77, 153-171.

[6] Caballero, R. J., E. Fahri and M. L. Hammour (2006): "Speculative growth: hints from the U.S. economy", American Economic Review 96, 1159-1192.

[7] de la Croix, D. and P. Michel (2002). A theory of economic growth. Cambridge University Press. 
[8] Diamond, D. W. and P. H. Dybvig (1983): "Bank runs, deposit insurance and liquidity", Journal of Political Economy 91, 401-419.

[9] Fahri, E. and J. Tirole (2012): "Bubbly liquidity", Review of Economic Studies 79, 678-706.

[10] Group of Thirty (2013): "Long-term finance and economic growth", Group of Thirty, Working Group on Long-term Finance, Washington.

[11] Hirano, T. and N. Yanagawa (2017): "Asset bubbles, endogenous growth, and financial frictions", The Review of Economic Studies 84, 406-443.

[12] Howitt, P. and P. Aghion (1998): Capital accumulation and innovation as complementary factors in long-run growth", Journal of Economic Growth 3, 111-130.

[13] Jordà, O., M. Schularick, and A. M. Taylor (2015) "Leveraged bubbles", Journal of Monetary Economics 76, S1-S20.

[14] Kamihigashi, T. (2008): "The spirit of capitalism, stock market bubbles and output fluctuations ", International Journal of Economic Theory 4, $3-28$.

[15] Kocherlakota, N. (1992): "Bubbles and constraints on debt accumulation", Journal of Economic Theory 57, 245-256.

[16] Kocherlakota, N. (2009): "Bursting bubbles: consequences and cures", mimeo, Federal Reserve Bank of Minneapolis.

[17] Lagos, R. (2010): "Asset prices and liquidity in an exchange economy", Journal of Monetary Economics 57, 913-930.

[18] Lagos, R. and R. Wright (2005): "A unified framework for monetary theory and policy analysis", Journal of Political Economy 113, 463-484.

[19] Lansing, K. (2008): "Speculative bubbles and overreaction to technological innovation", FRBSF Economic Letter 2008-18.

[20] Lansing, K. (2012): "Speculative growth, overreaction, and the welfare cost of technology-driven bubbles", Journal of Economic Behavior and Organization 83, 461-483.

[21] Le Van, C. and N.-S. Pham (2016): "Intertemporal equilibrium with financial asset and physical capital", Economic Theory 62, 155-199.

[22] Martin, A. and J. Ventura (2012): "Economic growth with bubbles", American Economic Review 102, 3033-58.

[23] Martin, A. and J. Ventura (2016): "Managing credit bubbles", Journal of the European Economic Association 14, 753-789. 
[24] Miao, J. (2014): "Introduction to economic theory of bubbles", Journal of Mathematical Economics 53, 130-136.

[25] Miao, J. and P. Wang (2018): "Bubbles and credit constraints", forthcoming in American Economic Review.

[26] Samuelson, P. A. (1958): "An exact consumption-loan model of interest with or without the social contrivance of money", Journal of Political Economy 66, 467-482.

[27] Scheinkman, J. A. (2013): "Speculation, trading and bubbles", Princeton University - Economic Theory Center Research Paper 050-2013.

[28] Shiller, R. J. (2000), Irrational Exuberance, Princeton University Press.

[29] Tirole, J. (1985): "Asset bubbles and overlapping generations", Econometrica 53, 1071-1100.

[30] Wehinger, G. (2011): "Fostering long-term investment and economic growth, summary of a high-level OECD financial roundtable ", $O E C D$ Journal: Financial Market Trends.

[31] Weil, P. (1987): "Confidence and the real value of money in overlapping generations models", Quarterly Journal of Economics 102, 1-22. 